\title{
Crosstalk of Intercellular Signaling Pathways in the Generation of Midbrain Dopaminergic Neurons In Vivo and from Stem Cells
}

\author{
Claude Brodski ${ }^{1, *}$, Sandra Blaess ${ }^{2, *}$, Juha Partanen ${ }^{3, *}$ and Nilima Prakash ${ }^{4, *}$ (C) \\ 1 Department of Physiology and Cell Biology, Zlotowski Center for Neuroscience, Faculty of Health Sciences, \\ Ben-Gurion University of the Negev, Be'er Sheva 84105, Israel \\ 2 Institute of Reconstructive Neurobiology, University of Bonn Medical Center, 53127 Bonn, Germany \\ 3 Faculty of Biological and Environmental Sciences, FIN00014-University of Helsinki, P.O. Box 56, \\ Viikinkaari 9, FIN-00014 Helsinki, Finland \\ 4 Department Hamm 2, Hamm-Lippstadt University of Applied Sciences, 59063 Hamm, Germany \\ * Correspondence: claude@bgu.ac.il (C.B.); sandra.blaess@uni-bonn.de (S.B.); \\ juha.m.partanen@helsinki.fi (J.P.); Nilima.Prakash@hshl.de (N.P.); \\ Tel.: +972-8647-7320 (C.B.); +49-228-6885-540 (S.B.); +358-504-485-808 (J.P.); +49-2381-8789-512 (N.P.)
}

Received: 30 November 2018; Accepted: 9 January 2019; Published: 15 January 2019

\begin{abstract}
Dopamine-synthesizing neurons located in the mammalian ventral midbrain are at the center stage of biomedical research due to their involvement in severe human neuropsychiatric and neurodegenerative disorders, most prominently Parkinson's Disease (PD). The induction of midbrain dopaminergic (mDA) neurons depends on two important signaling centers of the mammalian embryo: the ventral midline or floor plate (FP) of the neural tube, and the isthmic organizer (IsO) at the mid-/hindbrain boundary (MHB). Cells located within and close to the FP secrete sonic hedgehog $(\mathrm{SHH})$, and members of the wingless-type MMTV integration site family (WNT1/5A), as well as bone morphogenetic protein (BMP) family. The IsO cells secrete WNT1 and the fibroblast growth factor 8 (FGF8). Accordingly, the FGF8, SHH, WNT, and BMP signaling pathways play crucial roles during the development of the mDA neurons in the mammalian embryo. Moreover, these morphogens are essential for the generation of stem cell-derived mDA neurons, which are critical for the modeling, drug screening, and cell replacement therapy of PD. This review summarizes our current knowledge about the functions and crosstalk of these signaling pathways in mammalian mDA neuron development in vivo and their applications in stem cell-based paradigms for the efficient derivation of these neurons in vitro.
\end{abstract}

Keywords: dopamine; neuron; FGF8; SHH; WNT; BMP; Parkinson's disease; pluripotent stem cells; iPSC

\section{Introduction}

The major dopaminergic (DA) neuronal population of the mammalian brain is located in the ventral midbrain (VM) [1]. Confined to a relatively small territory within the VM, mDA neurons are organized into three cell groups, the retrorubral field or A8 group, the substantia nigra pars compacta (SNc) or A9 group, and the ventral tegmental area (VTA) or A10 group [1]. Neurons of the VTA project to the prefrontal cortex to form the mesocortical pathway, which is important for cognition (Figure 1) [2]. Impairment of the DA output to the prefrontal cortex has been implicated in schizophrenia and attention deficit hyperactivity disorder (ADHD) [3,4]. VTA neurons also send their axons to limbic structures to form the mesolimbic pathway linked to motivation, reward, and addiction behaviors. SNc neurons project to the dorsolateral striatum. These SNc projections constitute the 
mesostriatal pathway, a central modulator of locomotor activity. Reduced striatal DA output due to the degeneration of the SNc DA neurons is the major cause of motor symptoms observed in PD (Figure 1).

1 Mesocortical Pathway

- VTA neurons project to cortex (CTX)

- Modulates cognitive functions and emotions

- Dysfunction in schizophrenia, ADHD, and affective disorders

\section{Mesolimbic Pathway}

- VTA neurons project to nucleus accumbens (AC)

- Modulates motivation, reward, and emotions

- Dysfunction in drug addiction, affective disorders, and schizophrenia

\section{Nigrostriatal Pathway}

- SNc neurons project to striatum (STR)

- Controls motor function

- Degeneration causes motor symptoms in PD

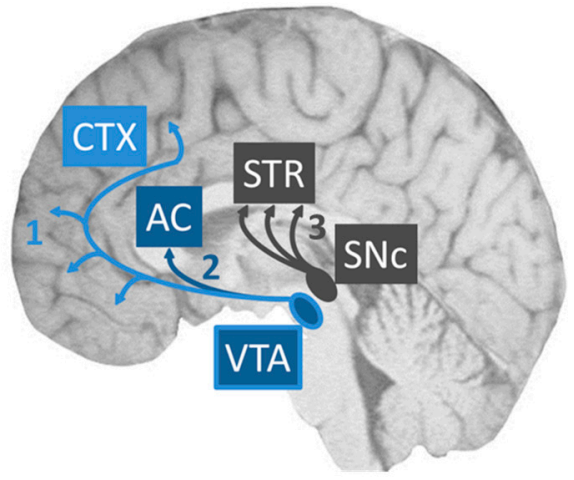

Figure 1. The three dopaminergic pathways originating in the midbrain. Projections, main functions, and major disorders associated with each pathway are listed on the left-hand side. A schematic depiction of the corresponding human dopaminergic pathways is shown on the right-hand side.

The mDA neurons show a remarkable diversity, which has been recognized only recently [5-7]. This diversity has been described in terms of their morphological characteristics [8], gene expression pattern [9], electrophysiological features [10], and their connectivity [11]. Such significant differences are determined during the development of the mDA neurons. The molecular mechanisms that underlie mDA progenitor proliferation, specification, and migration, though not yet fully understood, appear to be critical in creating different subsets of these neurons.

The central nervous system in mammals develops from the embryonic neural tube, which is initially divided into four parts: forebrain (prosencephalon), midbrain (mesencephalon), hindbrain (rhombencephalon), and spinal cord. Morphogens secreted from specific organizing centers within or nearby the developing neural tube guide the initial patterning of these regions and provide the neural stem cells (NSCs) with positional information that directs their development according to their location. The mDA neurons develop under the influence of the midbrain FP, containing $\mathrm{SHH}$-, WNT-, and BMP-secreting cells, and the IsO at the MHB, secreting WNT and FGFs from its rostral and caudal border, respectively [12].

Following the induction of the midbrain during embryogenesis [13], a distinct mDA progenitor domain is specified within the midbrain FP. In this domain, radial glia-like neural progenitors divide symmetrically to expand their pool and switch to asymmetric (neurogenic) divisions at the onset of neurogenesis ([14,15] reviewed in References $[9,12,16])$. The balance between self-renewal and cell cycle exit of the mDA neural progenitors, and the generation of the appropriate numbers of postmitotic progeny, is critical for the proper formation of $\mathrm{mDA}$ neurons. So far, four major signaling pathways activated by FGFs, SHH, WNTs, and BMPs have been identified in mammals to control the proliferation and specification of mDA progenitors in vivo (reviewed in References [9,12,17-19]). Downstream of these signaling pathways, expression of a series of transcription factors (TFs) is activated to regulate progenitor cell responsiveness to these morphogens (OTX2, LMX1A/B, and FOXA1/2; [20-28]), neurogenesis (MSX1/2 and NGN2; $[23,29,30])$, and mDA neuron differentiation and survival (EN1/2, NURR1, PITX3; [31-39]).

Parkinson's Disease (PD) is a prevalent and highly debilitating neurodegenerative disease [40]. For still not fully understood reasons, the SNc mDA neurons are particularly vulnerable to degeneration and their loss is a neuropathological hallmark of PD [12]. Currently, there is no cure for PD and treatments using the DA precursor L-DOPA or DA receptor agonists can only ameliorate the symptoms, 
but do not stop the progression of the disease. One of the most promising new approaches to treat PD is cell replacement therapy using human pluripotent stem cell (PSC)-derived mDA neurons, for which the first clinical trials are currently underway [41]. Moreover, stem cell-derived mDA neurons are also becoming an indispensable tool for PD modeling and drug screening. However, the differentiation of stem cells to mDA neurons requires the knowledge of the exact molecular mechanisms directing the embryonic development of mDA neurons in vivo. Current in vitro differentiation protocols for mDA neurons are based on the activation of the three signaling pathways, FGF, SHH, and WNT, which regulate the formation of mammalian mDA neurons in vivo [12,42-44]. Therefore, understanding how these pathways interact is expected to critically increase the yield and quality of stem cell-derived mDA neurons.

In this review, we will focus on the generation of mammalian mDA neurons. To investigate the development of these neurons in vivo, mouse mutants are the prime model. Conditional mouse mutagenesis provides extensive possibilities to determine specific effects of the inactivation of genes of interest with high spatiotemporal precision. However, caveats and drawbacks of these models need to be taken into consideration. The driver mouse lines do not always lead to a complete inactivation of the corresponding gene and may result in mosaicisms [45]. Insights from mouse mutants cannot necessarily be applied directly to the human situation, and direct pathway interactions are not easily determined [46]. Moreover, mouse models of PD generally do not recapitulate all features of the human disease [47], which is one main reason why patient-specific, stem cell-derived mDA neurons have gained substantial interest in recent years. To study the generation of these neurons in vitro, different mouse as well as human stem cells are widely used and will therefore be discussed in the following sections in more detail.

\section{Signaling Pathways in Midbrain Dopaminergic Neuron Generation In Vivo and In Vitro}

\subsection{FGFs/FGF8 Signaling}

\subsubsection{FGF Signaling Pathway in the Embryonic Midbrain}

Fibroblast growth factors (FGF1-22) are a family of secreted signaling molecules [48]. In a tissue, spreading and signaling of most FGFs are modulated by their interaction with the extracellular matrix, in particular heparan sulfate proteoglycans. FGFs affect their target cells by binding to cell surface receptors belonging to the receptor tyrosine kinase family (FGFR1-FGFR4). This results in activation of multiple downstream signal transduction cascades, in particular the mitogen-activated protein kinase (MAPK), phosphoinositide-3-kinase/protein kinase B (PI3K/AKT), phospholipase C gamma (PLC $\gamma$ ), and signal transducers and activators of transcription (STAT) pathways [48] (Figure 2). In addition to these canonical signal transduction mechanisms, signaling via nuclear FGFR localization has been suggested [49]. The initial transcriptional response to the FGF stimulation is similar in many cell types and often includes activation of expression of members of the Ets family TFs, such as ETV4 (PEA3) and ETV5 (ERM), as well as feedback signaling modulators, including Sprouty (SPRY) and dual specificity phosphatase (DUSP) gene products (Figure 2). The cellular response to the activation of the FGF-stimulated intracellular signaling cascade and the later FGF-induced gene expression changes are highly dependent on the type of the target cell. FGFs have been shown to regulate cell survival, proliferation, differentiation, migration, metabolism, axon guidance, and subcellular differentiation, such as synaptogenesis.

Several FGF family members regulate the development of the embryonic midbrain, including its $\mathrm{FP}$, which gives rise to mDA neurons. In particular, FGF8, expressed early in the entire rhombomere 1 and later in the posterior (Gbx2-positive) part of the $\mathrm{IsO}$, is highly important for midbrain development [50]. At the IsO, FGF8 is produced as two alternatively spliced isoforms, FGF8a and FGF8b. Of these, FGF8b has a higher receptor binding affinity and appears to carry out the majority of the signaling function [51]. Related FGFs, FGF17 and FGF18, are also expressed in the IsO in an FGF8-dependent fashion, but, in contrast to FGF8, in both the anterior (Otx2-positive) and posterior 
(Gbx2-positive) parts of the IsO. They appear to support the FGF8 functions but have weaker signaling capacity compared to FGF8b [51,52]. Other FGF family members have also been detected in the developing midbrain in different patterns. For example, FGF15 is expressed in the laterodorsal region, but not close to the MHB [53,54]. However, studies on FGF protein localization, detection of FGF receptor binding activity and expression of the proximal FGF target genes all suggest that, in the early embryonic midbrain, FGF growth factors form both molecular and activity gradients increasing towards the IsO $[55,56]$.

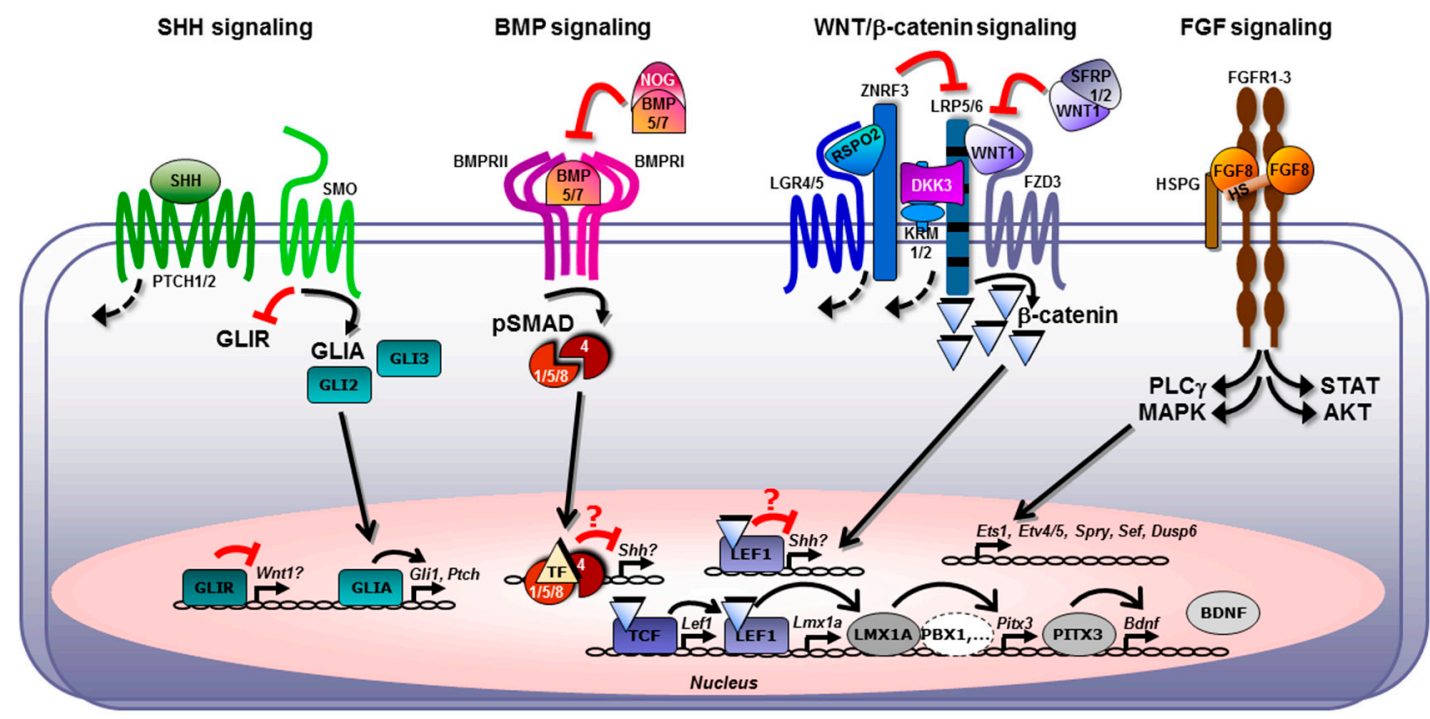

Figure 2. Signaling pathways in mDA neuron development. Schematic and simplified depiction of the main signaling pathways implicated in the generation and maintenance of mDA neurons in the mammalian embryo, SHH, BMP, WNT/ $\beta$-catenin, and FGF (from left to right), and their proven or yet unknown gene targets in the cell nucleus. Arrows indicate activation, crossbars indicate inhibition of the corresponding pathway or target molecule/gene. Stippled curved lines indicate endocytosis of the corresponding ligand-receptor/co-receptor complex. Question marks denote a still unclear target gene or mechanism in the corresponding pathway during mDA neuron development. See text for details and abbreviations.

Of the signal transducing FGF receptors, FGFR1, FGFR2, and FGFR3 are expressed in the embryonic midbrain. FGFR1 is broadly expressed throughout the midbrain neural progenitors, whereas FGFR2 and FGFR3 are not detected close to the MHB. Consistent with their patterns of expression, FGFR1, FGFR2, and FGFR3 redundantly receive FGF signals, FGFR1 being the main receptor close to the IsO $[57,58]$. FGFR function is regulated, both positively and negatively, by several proteins. Interestingly, the expression of many of the genes encoding for such regulatory proteins is stimulated by the FGF signaling pathway in the embryonic midbrain [59]. The positive regulators include canopy FGF signaling regulator 1 (CNPY1), which promotes FGFR maturation in the endoplasmic reticulum, and fibronectin leucine rich transmembrane protein 3 (FLRT3), a transmembrane protein shown to form a complex with FGFR [60-63]. On the other hand, FGF-induced negative feedback signal regulators, such as interleukin 17 receptor D (SEF/IL17RD), Sprouty related EVH1 domain containing (SPRED), SPRY and DUSP proteins, regulate various steps in the intracellular signal transduction pathway (reviewed in Reference [64]). The reason why FGF signaling induces both positive and negative feedback regulation remains largely unclear. It may regulate the timing of active FGF signaling, suggested to be important for the signaling outcome [65]. The negative feedback regulators also provide another means to shape the FGF signaling gradient in the developing tissue. 


\subsubsection{FGF-Regulated Developmental Processes in the mDA Neuron Progenitors}

Already 20 years ago, the discovery of FGF8 as an important signal of the IsO led to the demonstration of its requirement and potency in instructing the development of mDA neurons $[50,66]$. In the embryonic midbrain, FGF signaling has been suggested to control several developmental processes discussed below. Although many of these studies focused on the more dorsal regions of the midbrain, it is likely that these processes are also FGF-regulated in the developing mDA neuron progenitors in the VM.

After neural induction, FGF signaling is instrumental for both establishment and maintenance of the IsO at the MHB [50]. FGF8 is an integral part of a signaling network at the IsO, where the expression of FGF8 and WNT1 are dependent on each other (see Section 2.5.1). This fact also makes understanding of the direct versus indirect effects of FGF signaling more challenging in the in vivo models.

Following the establishment of the IsO, FGF8 signaling is important for the maintenance of the neural progenitor viability. Inactivation of FGF8 or FGFRs results in an increase of apoptotic cell death in the early embryonic midbrain neuroepithelium [57,67]. Although more prominent in the dorsal (alar) midbrain, increased apoptosis was also detected in the VM of the Fgfr mutants, where it occurred prior to the onset of mDA neuron differentiation [57].

FGF signaling regulates anterior-posterior $(\mathrm{A} / \mathrm{P})$ patterning and compartmentalization of the midbrain $[68,69]$. Strong FGF8b signaling can transform the midbrain tissue into rhombomere 1 /isthmus identity, positive for Gbx2 expression [70-72]. This may correspond to the observations that in rat explant cultures, FGF4 stimulation, likely resulting in a robust FGFR activation, yields serotonergic neurons characteristic for the ventral hindbrain [66]. Lower levels of FGF signaling from the IsO appear important for the A/P patterning of both the dorsal midbrain and the VM [73-75]. During mDA neuron development, early postmitotic neuronal precursors expressing tyrosine hydroxylase (TH) are produced in a relatively broad A/P region, starting from the diencephalic $\mathrm{p} 3$ domain and extending posteriorly up to the MHB. Recent fate mapping and transcriptional profiling studies suggest that the mDA neurons arise from progenitors derived from En1 expressing cells, which, in addition to the midbrain, encompass the basal region of the diencephalic $\mathrm{p} 1$ and $\mathrm{p} 2$ domains (this is in contrast to the alar region, where the Pax6/En1 boundary defines the diencephalon (p1)/midbrain border) [76,77]. In turn, the basal p3 domain belongs to the $D b x 1$ cell lineage and gives rise to neurons in the subthalamic and premammillary nuclei, which are non-dopaminergic, yet share the expression of many genes active in mDA precursors $[76,78]$. Although derived from the En1 expressing cell lineage, the basal $\mathrm{p} 1$ and p2 progenitors appear to later mostly downregulate $E n 1$ and En2 expression [75]. The TH-expressing precursors derived from these regions are also negative for the expression of $E n 1, E n 2$, and many other mDA markers detected in the embryonic midbrain. This difference appears to be due to FGF signaling in the midbrain. If FGFRs are inactivated in the midbrain neuroepithelium, both the ventral progenitors and the TH-expressing precursors derived from them transform to a ventral diencephalic identity, including the loss of $E n 1$ and $E n 2$ expression [75]. In the Fofr mutant embryos, TH expression appears to be later downregulated without apparent cell death. Similarly, in conditional $F g f 8$ mutant mice, TH-expressing precursors are initially produced in the embryonic midbrain, but TH-positive mDA neurons are not detected in the perinatal brain $[67,79]$. Whether the loss of TH expression reflects the normal fate of the diencephalic $\mathrm{p} 1 / \mathrm{p} 2$-derived $\mathrm{TH}$-positive precursors remains unclear. Understanding the contribution of the diencephalic TH-expressing precursors to the $\mathrm{mDA}$ nuclei would require fate-mapping tools able to distinguish the basal midbrain and $\mathrm{p} 1 / \mathrm{p} 2$ domains. The early embryonic brain patterning generates two main types of $\mathrm{mDA}$ neurons along the $\mathrm{A} / \mathrm{P}$ axis of the midbrain and diencephalon, postnatal development extending this diversity to at least five molecularly distinct subtypes $[46,80]$. However, both of the embryonic mDA neuron subgroups appear to be molecularly related to the midbrain-derived precursors.

In addition to the regional identity, both gain-of-function (GOF) and loss-of-function (LOF) studies suggest that FGF signaling regulates the balance between neural progenitor maintenance and neurogenic cell cycle exit in the embryonic midbrain, including the developing mDA neurons $[56,81]$. 
In the neural progenitors, the basal process may transduce the basal lamina-derived FGF signals to promote Hes1 and Sox3 expression, which in turn inhibit proneural gene expression and neurogenic cell cycle exit $[56,82]$. When FGF signaling is inactivated, Hes1 and Sox3 expression is downregulated and the embryonic VM precociously generates TH-positive precursors. Consistently, the early production of TH-expressing precursors is also increased in Hes1 mutant embryos [83]. The exact molecular identity of the FGF signal promoting neural progenitor maintenance remains unclear. Nevertheless, it has been shown that, compared to neuroepithelial patterning, lower signaling levels stimulated by FGF8a, FGF17, or FGF18 can promote progenitor proliferation [72,84]. Interestingly, some of the FGFs appear to have antagonistic functions. In particular, FGF15, expressed throughout the dorsolateral midbrain, promotes neurogenic differentiation rather than progenitor proliferation [54]. The mechanism behind the apparently opposite functions of FGF8 and FGF15 in progenitor regulation remains unclear.

During later development of the mDA system, FGFs have additional functions, including axon guidance [85]. Interestingly, the mature mDA neurons express certain FGF family members, such as FGF20, possibly regulating their survival and other cellular functions [86-89]. Notably, the human FGF20 gene locus has been associated with PD [90], although the mechanisms behind this remain unclear.

\subsubsection{FGF Signaling Promotes mDA Neuron Differentiation In Vitro}

In vitro, FGF signaling regulates the proliferation and differentiation of NSCs, including embryonic neural progenitor cells isolated from the midbrain [91,92]. Moreover, FGF signaling is required for mDA neuron development and exogenous FGF8 induces mDA neuron differentiation in neural explants [66]. These findings, together with the knowledge of FGF functions during midbrain development in vivo, motivated the design of protocols for mDA neuron differentiation from neural progenitors, embryonic stem cells (ESCs), induced PSCs (iPSCs), or reprogrammed somatic cells, such as fibroblasts [12,93-96]. In the cell culture, exogenous FGF stimulation may mimic signaling events at various developmental steps, including PSC neuralization, and NSC patterning, proliferation and maintenance. Underlining the importance of fine-tuning the neural patterning, a recent study shows a correlation between the expression of posterior midbrain genes, including many FGF target genes, and the success of intracerebral grafting of ESC-differentiated mDA precursors [97]. Furthermore, patterning of ESC-derived VM progenitors with a timed delivery of FGF8 resulted in posterior midbrain-type mDA neuron precursors, which in turn gave rise to dopamine-rich grafts able to alleviate symptoms in a rat model of PD [97-99]. These results are consistent with the observed requirement of FGF signaling in patterning of the VM in vivo. Combined with the modulation of the other signaling pathways, in particular SHH and WNT, FGF signaling may be used for more precise patterning of the neural progenitor cells to give rise to cultures of correctly specified mDA neurons and their subtypes, with little contamination of related cell lineages [76,97].

\subsection{SHH Signaling}

\subsubsection{The SHH Signaling Pathway}

Hedgehogs are secreted morphogens with multiple functions during embryonic development. In vertebrates, there are three family members: Desert Hedgehog (DHH), Indian Hedgehog (IHH), and Sonic Hedgehog (SHH) [100,101]. SHH is the Hedgehog protein that is essential for the developing nervous system [102]. The core pathway through which SHH (as well as IHH and DHH) signaling is transduced in mammals consists of the twelve-pass transmembrane receptor Patched (PTCH), the G-protein coupled receptor Smoothened (SMO) and three Gli TFs (glioma-associated oncogene; GLI1-3) [100] (Figure 2). In the absence of SHH, the activity of SMO is suppressed by PTCH [103], and GLI2 and GLI3 are proteolytically cleaved to repressor forms (GLIR) [104,105]. GLI3R is the main repressor downstream of SHH signaling and inhibits the transcription of SHH target genes [106,107]. In the presence of SHH, the inhibition of SMO by PTCH is released [103]. As a consequence, the formation 
of GLIR proteins is attenuated and GLI2 and GLI3 are present as full-length activators (GLIA) [104,105] (Figure 2). GLI2A has the main activator role downstream of SHH, GLI3A has only a minor function as activator [108-110]. GLIA in turn induce the transcription of GLI1, a constitutive activator in the SHH pathway that enhances the activating side of the SHH signaling pathway $[108,109,111]$. Another target gene of activated $\mathrm{SHH}$ signaling is $\mathrm{PTCH}$, adding a negative feedback loop to the signaling pathway [112]. Both GLI1 and PTCH expression have been used as readout for activated SHH signaling $[113,114]$ (Figure 2). An important aspect of SHH signaling is that the key components of the SHH signaling pathway, PTCH, SMO and the GLI proteins are localized in and around the primary cilium. Primary cilia are a single copy, non-motile membrane protrusion present in most mammalian cells and are thought to serve as a receiver of extracellular signals. The regulated transport of PTCH, SMO, and GLI proteins in and out of the primary cilia is critical for the processing of GLI proteins into their activator and repressor forms [115]. Thus, the loss of functional primary cilia results in phenotypes similar to the ones observed when both GLIA and GLIR function are inactivated (i.e., in Gli2/3 double mutants) [115].

In addition to this core signaling pathway, there are several PTCH co-receptors that are required for the binding of $\mathrm{SHH}$ with high affinities, such as growth arrest-specific 1 (GAS1), CAM-related/downregulated by oncogenes (CDO), and brother of CDO (BOC) [116,117]. Additional components downstream of PTCH and SMO include SUFU (suppressor of fused), which regulates SHH pathway activity negatively; KIF7, which is important for the transport of GLI2/3 through the primary cilium as well as several protein kinases (protein kinase A (PKA), casein kinase 1 (CK1), and glycogen synthase kinase $3 \beta$ (GSK3 $\beta)$ ), that phosphorylate GLI2/3 and thus mark them for proteolytical processing [100].

\subsubsection{Expression of Shh Pathway Components in the Ventral Midbrain}

Midbrain dopaminergic neurons are derived from a LMX1A/B (LIM homeobox transcription factor 1)- and FOXA1/2 (forkhead/winged helix transcription factors)-positive progenitor domain that is established around day 9.5 of embryonic development (E9.5) at the ventral midline of the mesencephalon. $\mathrm{SHH}$ and its downstream pathway components show a dynamic expression in the mesencephalic ventral midline. In the developing murine VM, Shh is initially expressed in the notochord that underlies the forming neural tube (starting at E7.5). Notochord-secreted SHH induces GLI2A in the midline of the neural tube (the FP) between E8.0 and E8.5. The activation of the SHH signaling pathway results in the expression of Gli1 and Foxa1/2 in the FP. FOXA1/2 are in turn necessary to induce expression of Shh in FP cells around E8.5 [118-122]. Shh expression expands over the following days encompassing not only the FP but also part of the adjacent basal plate (BP; up to E10.5) and thus the entire LMX1A-positive mDA progenitor domain. At E11.5, Shh expression is downregulated at the ventral midline, leaving two stripes of cells lateral to the ventral midline that continue to express $S h h$ in the subsequent days and that partially overlap with the mDA progenitor domain [120,122-125]. After Shh expression is induced in the ventral midline, Gli2 is downregulated in the SHH-positive FP and BP areas, but expression is maintained in the lateral and dorsal progenitors in the midbrain. Gli3 expression is restricted to the alar plate after E8.0. Both Gli1 and Ptch are strongly expressed in a narrow domain just lateral to the $\mathrm{SHH}$-expressing domain but are absent from the SHH-expressing domain itself. Thus, with the expansion of the Shh-expressing domain between E8.0 and E12.5, Gli1 and Ptch expression domains move further lateral within the BP and only overlap with the mDA progenitor domain before E10. Smo is expressed throughout the VM [121-127]. As for the PTCH co-receptors, CDO expression in the ventral midline has been shown at E9.5 and E12.5 [128,129], while GAS1 expression is restricted to the dorsal midbrain and is only detected at E12.5 and not at later stages [130]. BOC expression has not been analyzed in the VM.

In summary, all the components necessary for activating the canonical SHH pathway (SMO, PTCH, GLI1, GLI2) are expressed in the mDA progenitor domain during early neural development but are downregulated after E9.5 (except for SMO). Moreover, neither GLI1 nor PTCH are detected in differentiated $\mathrm{mDA}$ neurons, indicating that canonical $\mathrm{SHH}$ signaling does not play a role in 
differentiated mDA neurons $[127,130]$. SMO is maintained in differentiated mDA neurons where it functions in non-canonical signaling during axon pathfinding [131].

\subsubsection{Fate Mapping of SHH-Expressing and SHH-Responding Progenitors in the VM}

The dynamic expression patterns of Shh and Gli1 in the mDA progenitor domain have been used to determine whether different mDA progenitor domains give rise to specific neuronal subpopulations in the VM. A genetic fate-mapping approach that labels all Shh-expressing cells in a permanent manner shows that most (if not all) mDA neurons are derived from Shh-expressing cells. In addition, Shh-expressing cells also generate non-mDA neurons in a number of other VM nuclei, including neurons in the red nucleus $[124,132,133]$. Besides providing insight into the ventral midline origin of mDA neurons, these results in combination with additional fate-mapping studies demonstrated that the mesencephalic FP is neurogenic, in contrast to FP cells in the spinal cord and hindbrain, which act as organizers for the surrounding tissue but do not give rise to neurons $[14,132,134,135]$. To generate fate-maps with temporal and spatial resolution that reflect the dynamic expression of Shh and the SHH signaling readout Gli1, genetic inducible fate-mapping has been used to follow the fate of Shh-expressing and Gli1-expressing (equivalent to SHH-responding) $\mathrm{mDA}$ progenitors and their descendants at various time points of development. These fate-maps show that cells within the mDA progenitor domain (that express Gli1 at E7.5 or Shh at E8.5) preferentially give rise to SNc neurons, whereas cells that express Gli1 or Shh later in development (at E9.5 or E11.5, respectively) almost exclusively give rise to VTA neurons [123,136]. After E9.5, Gli1-expressing cells do no longer give rise to mDA neurons, since the Gli1 expression domain lies outside of the mDA progenitor domain. The contribution of Shh-expressing cells to mDA neurons tapers off after E11.5, probably because the neurogenic potential of the progenitors decreases $[123,136,137]$. The existence of two mDA progenitor domains with distinct fate potential was corroborated by the analysis of TF expression domains in the $\mathrm{mDA}$ progenitor domain and in differentiated mDA neurons: OTX2 is expressed at high levels in the lateral mDA progenitor domain and is largely restricted to the VTA in differentiated mDA neurons. The medial mDA progenitor domain expresses SOX6, this TF is expressed in differentiated $\mathrm{mDA}$ neurons of the SN [138].

\subsubsection{In Vivo Function of the SHH Signaling Pathway}

The first evidence that $\mathrm{SHH}$ signaling plays an important role in the induction of mDA neurons came from in vitro studies and ectopic expression of Shh or Gli1 in the midbrain of transgenic mice [66,139,140]. This was corroborated with LOF experiments in the mouse: inactivation of the SHH signaling pathway in Shh null or Gli2 null mutants results in the loss of most VM structures, including the (almost) complete absence of the mDA progenitor domain and the mDA neuronal population $[110,121,141]$.

Conditional gene inactivation (cKO) of Smo, Gli2, Gli2/Gli3, or Shh around E8.5 in the midbrain and anterior hindbrain using Engrailed1 (En1)-Cre mice does not result in the loss of the entire mDA progenitor domain $[120,125,142,143]$, likely because the partial induction of the mDA progenitor fate by SHH signaling occurs earlier than E8.5: as described above, cells that respond to SHH (express Gli1) are already observed in the ventral midline around E7.5 $[123,136,144]$. Notably, the phenotypes vary in their severity depending on which component of the pathway has been conditionally inactivated. In Smo cKO mutants, only very few $\mathrm{mDA}$ progenitors are induced and the number of mDA neurons is severely reduced [120]. In Sh, Gli2, or Gli2/Gli3 cKO mutants, the numbers of mDA progenitors and $\mathrm{mDA}$ neurons are reduced by half compared to the wild-type $[120,125,142,143]$. The difference between Smo and Gli2 cKO or Gli2/Gli3 cKO mutants is likely due to an increase in GLIR in Smo cKO mutants, which results in massive apoptosis in the basal and alar plate [120]. In the Shh cKO mice, the phenotype is milder than in the Smo cKO mice, since SHH signaling appears to be still weakly activated judging by the faint Gli1 and Ptch expression in the BP [125]. The partial activation of the pathway suggests that $\mathrm{SHH}$ is still present in the extracellular space of the VM. One potential source for SHH may be the BP of the adjacent posterior hypothalamus [145]. 
Mutant (cKO) mice, in which Smo was inactivated using Shh-Cre, had mild and transient phenotypes in $\mathrm{mDA}$ progenitors and during $\mathrm{mDA}$ neurogenesis that do not affect the overall number of mDA neurons [122,124]. GOF experiments confirm the minor role of SHH signaling in mDA development at this time point: expression of a constitutively-active SMO in Shh-expressing cells results in only a transient increase in the size of the mDA progenitor domain [124]. Finally, inactivation of Smo or Gli2 after E10.5 using Nestin-Cre does not result in any discernable phenotype in the mDA progenitor domain or in the number of mDA neurons [120]. However, inactivation of Smo at this time point leads to axonal pathfinding defects in a small subset of mDA neurons [131].

These gene inactivation approaches have also been used to explore whether $\mathrm{SHH}$ signaling might contribute to setting up distinct mDA progenitor domains. In Gli2 cKO mice, the $50 \%$ reduction in the size of the mDA progenitor domain is mainly due to the loss of lateral mDA progenitors. Consistent with the genetic inducible fate-mapping data that show that these progenitors contribute preferentially to VTA neurons (see Section 2.2.3.), the reduction in mDA neurons in the adult brain of these mouse mutants can be largely attributed to a loss of VTA DA neurons [143]. Inactivation of the PTCH co-receptor $C$ do also results in a specific effect on VTA DA neurons. In Cdo null mice, proliferation in the VM ventricular zone is increased at E12.5 compared to controls, and in postnatal brains an increased number of VTA (but not SNc) DA neurons has been reported [129]. However, another study reports a severe decrease in the number of mDA neurons in Cdo null mice at E13.5 [128]. This may suggest that there is a transient delay in neurogenesis in Cdo null mice that is later (over)compensated. A detailed birthdating analysis in mutants in which Smo was inactivated with Shh-Cre shows transient effects of SHH signaling inactivation on the generation of VTA neurons: a transient increase in $\mathrm{mDA}$ progenitor proliferation at E11.5 is correlated with an increased contribution to the VTA, while at E13.5, increased cell cycle exit results in a depletion of proliferating mDA progenitors and reduced contribution to the VTA. The combination of transient increase and later depletion leads to no obvious change in the overall number of mDA neurons [122].

The importance of primary cilia for SHH signaling has also been demonstrated in the context of mDA progenitor induction. In a mouse mutant carrying two hypomorphic alleles for a gene encoding one of the ciliary transport proteins, IFT88, primary cilia function is defective but SHH signaling is not completely abolished. Small, rosette-like clusters maintain their ability to express Shh and/or Gli1, and a few mDA neurons are induced [142]. Conditional inactivation of Ift 88 using En1-Cre mice results in a severe loss of primary cilia and in inactivation of the $\mathrm{SHH}$ signaling pathway before $\mathrm{E} 9.5$, and a phenotype in the mDA progenitor domain and in differentiated mDA neurons that is comparable to Gli2 cKO or Gli2/Gli3 double-cKO mutants [142]. Conditional inactivation of Kif3a, encoding a kinesis motor protein important for cilium assembly and maintenance, abolishes primary cilia and SHH signaling in the VM only after E9.5 and results in a transient phenotype, in which the mDA progenitor domain is reduced but the number of differentiated mDA neurons in the prenatal brain is comparable to controls [146].

The combined insights from gene expression studies, fate mapping and gene inactivation approaches demonstrate that there is a critical period in which SHH plays a role in the development of mDA progenitors that ends around $\mathrm{E} 9.5$ in the mouse.

\subsubsection{Function of SHH Signaling in the Generation of mDA Neurons from PSCs}

Generation of mDA neurons from PSCs for cell replacement strategies in PD and/or disease modelling has been pursued for many years. Initially, these efforts were hampered, since the obtained neurons did not display all the principal characteristics of authentic mDA neurons (e.g., they lacked FOXA2 expression) and showed poor survival after transplantation [147]. The finding that mDA neurons are generated from FP-like, SHH-expressing cells was crucial for setting up protocols that allow efficient and high-yield production of mDA neurons from human PSCs. Since FP cells are established as a cell lineage distinct from BP neuronal progenitors during early neural development [148], this was an essential step in generating authentic mDA neurons in vitro. The Studer lab first implemented this 
concept to generate FP-type cells from PSCs [149]. Fasano and colleagues directly differentiated human ESCs into FP cells by adding high doses of SHH at early stages of a neural differentiation protocol that uses two BMP/transforming growth factor beta (TGF $\beta$ ) ("dual SMAD") inhibitors (day 1-9). FP cells were identified based on expression of FOXA2 and secretion of Netrin and SHH. These FP cells had anterior characteristics, but adding retinoic acid, FGF8, or WNT1 together with SHH shifted their fate posteriorly. In particular, addition of WNT1 resulted in FP cells with midbrain phenotypes as assessed by expression of EN1, LMX1B and Corin [149]. These insights were then utilized to generate neurons with the cardinal features of mDA neurons from human PSCs. To this end, the above described FP induction protocol was modified: SHH and FGF8 signaling is activated from day 1-7 of neural differentiation, followed by the activation of WNT signaling from day 3 onwards. After 11 days, this protocol yields midbrain FP cells and after 25 days, neurons with the characteristic expression profile of mDA neurons [43]. A slightly different protocol, in which SHH and WNT signaling were activated from day 0 to day 9 of neural differentiation was established by Kirkeby et al. and also results in the successful generation of authentic mDA neurons [150]. Importantly, in the context of cell replacement strategies, when the generated $\mathrm{mDA}$ neurons were transplanted into the brain of rats or monkeys they survived over several months, showed functional integration and improved behavioral outcomes in animals with lesions in the SNc $[43,150,151]$. Based on these results, protocols have been further refined to generate high yields of mDA neurons from PSCs and the first clinical application of hPSC-derived mDA neurons is now pursued for cell replacement in PD patients [41,99].

\subsection{WNT Signaling}

\subsubsection{WNT Signaling Pathways and Mechanisms}

After the discovery of an involvement of the FGF8 and SHH signaling pathways in the development of mDA neurons in mammals [66,139] (Sections 2.1 and 2.2), the prominent role of the WNT signaling pathways in $\mathrm{mDA}$ neuron generation in vitro (in the culture dish) and in vivo (in mice) was revealed only a decade later [152-154]. Meanwhile, both FGF8/SHH and WNT proteins or agonists are routinely used for the directed differentiation of human PSCs into mDA neurons (reviewed by $[155,156])$. The distinct WNT signaling pathways known so far in mammals are briefly summarized in the next two paragraphs, but the reader is referred to several recent reviews on the subject for more detailed information [157-161].

The 19 mammalian WNTs are secreted, which are lipid-modified (palmitoylated) glycoproteins that bind to a particular class of seven-pass transmembrane domain proteins, the frizzled (FZD) receptors (10 in mammals) [157] (Figure 2). Mounting evidence has shown that, because of their lipid modification, WNTs are very hydrophobic and short-range signaling molecules rather than classical morphogens. The highly regulated release of WNT molecules from the cell surface or within extracellular vesicles (exosomes), however, also enable the action of WNTs over longer distances [157]. Upon binding to their FZD receptors, WNT signals can be transduced via distinct pathways in vertebrate cells: the best studied pathway is the WNT/beta-catenin ( $\beta$-catenin, Ctnnb1) or "canonical" pathway [159], whereas less is known about the "non-canonical" WNT/planar cell polarity (PCP) and calcium $\left(\mathrm{Ca}^{2+}\right)$ pathways [161]. The hallmark of the WNT/ $\beta$-catenin pathway is the cytosolic accumulation of "free" (not bound to cadherins) and N-terminally unphosphorylated $\beta$-catenin after binding of WNT to its FZD receptor and another single-pass transmembrane protein, the low-density lipoprotein receptor-related protein (LRP) $5 / 6$ co-receptor (Figure 2). This is due to the not yet fully understood inactivation of a so-called "destruction complex" consisting of the scaffolding proteins axin and adenomatosis polyposis coli, the serine-threonine kinases CK $1 \alpha / \delta(\mathrm{Csnk} 1 \mathrm{a} / \mathrm{d})$ and GSK $3 \alpha / \beta$, and the beta-transducin repeat-containing E3 ubiquitin-protein ligase ( $\beta \operatorname{TrCP}, \mathrm{Btrc})[157,159]$. In the absence of a WNT signal, constitutive and sequential phosphorylation of serine residues in the $\beta$-catenin $\mathrm{N}$-terminus by $\mathrm{CK} 1$ and GSK3 is recognized by $\beta \operatorname{TrCP}$, which poly-ubiquitinates $\beta$-catenin thereby targeting it for proteasomal degradation. In the presence of a WNT signal and upon inactivation 
of the destruction complex, stabilized (unphosphorylated) $\beta$-catenin in the cytosol is relocated to the cell nucleus, where it binds to members of the high mobility group TF family, including lymphoid enhancer binding factor 1 (LEF1) and the T cell factors TCF7, TCF7L1, and TCF7L2 (Figure 2). In the absence of a WNT signal/nuclear $\beta$-catenin, LEF1/TCFs are associated with transcriptional repressors such as groucho/transducin-like enhancer of split proteins, which inhibit the activation of LEF1/TCF-bound WNT/ $\beta$-catenin target genes. Displacement of these transcriptional repressors by $\beta$-catenin and recruitment of co-activators, such as pygopus and B cell CLL/lymphoma 9, to the DNA-bound LEF1/TCF complex leads to the activation of a broad but context-specific variety of $\mathrm{WNT} / \beta$-catenin target genes. Several of these target genes are involved in the regulation of the cell cycle and proliferation of tissue-specific stem cells, whereas other targets of this signaling pathway participate in the acquisition of a particular cell fate by their progeny. It has therefore been suggested to rename the WNT / $\beta$-catenin signaling pathway as the "cell fate" WNT pathway [158]. This signaling pathway is inhibited or at least attenuated by several antagonists, including secreted proteins that either bind and sequester the WNT ligand directly, such as secreted frizzled-related proteins (SFRPs), inactivate the WNT ligand enzymatically, or interact with the LRP co-receptors and other single-pass kringle containing transmembrane proteins (KREMEN1/2) to induce their rapid internalization, such as the dickkopf (DKK1-4) family, thereby inhibiting the formation of an active WNT-FZD-LRP complex [157] (Figure 2). The availability of extracellular WNT proteins and cell surface FZD receptors is also controlled by other transmembrane proteins, such as the WNT N-terminal cleaving metalloproteases TIKI1/2 (Trabd) or the ring finger E3 ubiquitin ligases ZNRF3 and RNF43, which ubiquitinate the FZD receptors to promote their internalization and subsequent proteasomal degradation [157]. Notably, the secreted R-spondins (RSPO1-4) act as WNT agonists in this context by binding to the seven-pass transmembrane domain leucine-rich repeat-containing G protein-coupled receptors (LGR4-6) and inhibiting the ZNRF3 and RNF43 E3 ubiquitin ligases, thus augmenting the availability of FZD receptors at the cell surface (Figure 2). The disheveled (DVL) protein is another important component of WNT signal transduction in both the "canonical" and "non-canonical" pathways. Upon WNT binding to the FZD receptor, DVL is hyperphosphorylated and associates with the intracellular C-terminal end of this receptor, but its precise function in this context is not yet understood $[157,159]$.

WNT ligands, FZD receptors, and the intracellular protein DVL also participate in the $\beta$-catenin-independent "non-canonical" WNT pathways [160]. These pathways, however, divert at this level and possess alternative co-receptors, such as the single-pass transmembrane receptor tyrosine kinase-like orphan receptor (ROR1/2) and receptor-like tyrosine kinase (RYK), as well as alternative intracellular effectors including the small GTPases RHO, RAC, and CDC42; c-JUN $\mathrm{N}$-terminal kinase (JNK, Mapk8); and the AP-1 complex in the WNT/PCP pathway. In the WNT/Ca ${ }^{2+}$ pathway, the release of intracellular $\mathrm{Ca}^{2+}$ causes the activation of $\mathrm{Ca}^{2+}$-dependent protein kinases, such as protein kinase $\mathrm{C}$ and $\mathrm{Ca}^{2+} /$ calmodulin-dependent protein kinase $\mathrm{II}$, and of the $\mathrm{Ca}^{2+}$-dependent phosphatase Calcineurin, and subsequently of the nuclear factor of activated T cells (NFAT) family of TFs $[160,161]$. The WNT/PCP and WNT/Ca ${ }^{2+}$ pathways are mostly implicated in the acquisition of cell polarity, morphogenetic (convergent extension) movements, cell migration and neurite extension, and appear to antagonize the WNT/ $\beta$-catenin pathway in several instances. These "non-canonical" WNT signaling pathways have therefore been proposed to be re-named as "cell polarity" pathways [158]. However, the proliferation or acquisition of a particular fate by, and polarization or migration of, one and the same cell are most likely strongly interconnected, suggesting that a strict separation of both processes and WNT signaling pathways during mammalian development is not possible in many cases.

\subsubsection{WNT Signaling in Mammalian mDA Neuron Development In Vivo}

The first indication that WNT signals might play a role in the generation of bona fide mDA neurons came from a study showing that both $W n t 1$ and $W n t 5 a$ are expressed in the VM of the 
midgestational mouse embryo, and that the treatment of primary cells derived from the rodent VM with WNT1- or WNT5A-conditioned media promotes the generation of TH- and NURR1-positive mDA neurons in vitro ([152]; reviewed in Reference [162]). Whereas WNT1-conditioned media appeared to increase primarily the proliferation of $\mathrm{mDA}$ progenitors and to a lesser extent their differentiation into mature mDA neurons in these cultures, WNT5A-conditioned media did not affect the proliferation of VM progenitors but enhanced to an even greater extent than WNT1 their differentiation into Pitx3- and TH-expressing mDA neurons [152]. Subsequent in vivo analyses of Wnt1 LOF (Wnt1 null, En1-Cre conditional, and swaying hypomorphic) mutant mice revealed an initial (at E11.5) strong reduction and later (after E12.5) complete loss of PITX3- and TH-positive mDA neurons in the Wnt1 null and conditional mutant VM $[153,163]$, and a preferential loss of VTA DA neurons in the hypomorphic mice ([79]; reviewed in Reference [18]). Moreover, laterally (in the BP) positioned TH-positive but PITX3-negative cells in the Wnt1 null and conditional mutant VM were reported as ectopically positioned mDA neurons in these mutants $[163,164]$. Because of the recent finding that several genes used as bona fide "mDA markers," especially Foxa1/2, Lmx1a/b, and Nurr1, are also expressed in the rostral diencephalon (p3 domain) and particularly in developing hypothalamic neurons $[76,77]$, it might well be that these TH-positive cells are not genuine mDA neurons but rather belong to the diencephalic (hypothalamic) DA groups [165]. In contrast to the Wnt1 mutant mice, the Wnt5a null mutants showed the opposite phenotype: a transient increase of TH-positive $\mathrm{mDA}$ neurons at E14.5 that is preceded by an increased proliferation of FP progenitors and increased numbers of NURR1-positive mDA precursors but delayed differentiation of these precursors into TH- and NURR1-expressing mDA neurons at E12.5 ([154]; reviewed in Reference [162]). In addition, a shortening of the $\mathrm{A} / \mathrm{P}$ and broadening of the mediolateral midbrain axis as well as a disturbed apico-basal orientation of the VM neuroepithelial cells indicated a convergent extension and cell polarity defect in the Wnt5a null embryos [154]. Purified WNT5A protein indeed acts in the WNT/PCP pathway via DVL phosphorylation via CK1 and subsequent RAC1 activation in DA cells $[154,166,167]$. These results suggested that during mDA neuron development in vivo, WNT1 is the more important WNT controlling the generation of $\mathrm{mDA}$ progenitors and precursors, and their correct differentiation into mDA neurons. Moreover, they also suggested that WNT1 activates the WNT / $\beta$-catenin ("cell fate") pathway, whereas WNT5A stimulates the WNT/PCP ("cell polarity") pathway, and that both WNTs partly synergize with and antagonize each other during this process. Ensuing analyses of Wnt1 and Wnt5a double null mutant and conditional $\beta$-catenin (because Ctnnb1 null embryos die very early [168]) mutant mice corroborated these assumptions (reviewed in References [17,162]. The proliferative defect in the Wnt1 null VM is partly rescued by the simultaneous loss of Wnt5a in the Wnt1/Wnt5a double null embryos, whereas the strong reduction of TH/NURR1-positive mDA neurons in the Wnt1 null embryos and the midbrain morphogenesis defects of the Wnt5a null mutants are both potentiated in the Wnt1/Wnt5a double null mutants [164]. The conditional $\beta$-catenin LOF (using Shh-Cre, Th-IRES-Cre, and $R 26-C r e E R T$ drivers) or GOF (by deleting the $\mathrm{N}$-terminal $\beta$-catenin phosphorylation sites using Shh-Cre, Th-IRES-Cre, and En1-Cre drivers) mutant mice, on the other hand, show a decrease or increase and even ectopic generation in the rostral hindbrain, respectively, of NURR1-positive mDA precursors and TH/PITX3-expressing mDA neurons [135,169-173]. Notably, the conditional deletion of $\beta$-catenin also affects the $\beta$-catenin-containing (bound to cadherins) adherens junctions as well as centrosome formation and mitotic spindle orientation and thus the integrity and polarity of the mutant VM tissues [172,174], revealing the intricate functional relationships between WNT signaling and other intracellular components during development. Similarly, the "artificial" stabilization of $\beta$-catenin because of the deletion of the $\mathrm{N}$-terminal phosphorylation sites, leading to a probably excessive WNT / $\beta$-catenin signaling in these mutant mice, disrupts the normal differentiation of NURR1-positive mDA precursors into TH- and PITX3-expressing mDA neurons $[135,171,173]$. The conditional $\beta$-catenin mutants thus highlighted the need of a precisely balanced WNT/ $\beta$-catenin signal for the proper specification of proliferating mDA progenitors and their differentiation into mature mDA neurons. 
Consistent with the findings described above, mouse mutants for other components of the $\mathrm{WNT} / \beta$-catenin signaling pathway expressed in the murine VM, such as the "canonical" WNT2 and WNT7A ligands and the LRP6 co-receptor, revealed a persistent (Wnt2 null mice) or transient (Wnt7a and Lrp6 null mice, probably due to the compensation by other WNTs/LRPs) reduction of NURR1-positive mDA precursors and TH-positive mDA neurons at late midgestational stages [175-177]. Conversely, single and double null mutant mice for the FZD3 receptor, a ubiquitously expressed $F z d$ receptor in neural tissues [178,179], and FZD6 receptor, a Fzd receptor that is specifically expressed in the caudal VM of the midgestational mouse embryo $[178,179]$, exhibit $\mathrm{mDA}$ and midbrain phenotypes. These alterations are consistent with the known function of these receptors in the WNT/PCP pathway $[161,180]$. Mutants show a transient reduction of TH-positive mDA neurons at E12.5 that recovers at E13.5 and a mediolateral broadening of the mDA domain is evident in the Fzd3 null embryos, whereas Fzd6 null embryos do not show any obvious mDA phenotype, and Fzd3/Fzd6 double null mutants present with a severe midbrain morphogenesis defect and broadening of the mDA domain but otherwise normal numbers of mDA neurons [181]. Accordingly, mouse null mutants for Sfrp1 or Sfrp2, the only two Sfrp genes expressed in the murine VM/mDA domain, do not exhibit any defects in mDA neuron development, whereas Sfrp1/Sfrp2 double null mutant mice have an almost identical phenotype to the Wnt5a null mutants, suggesting that these WNT/ $\beta$-catenin antagonists promote WNT/PCP signaling in the mouse VM [182]. Mouse null mutants for the Ryk co-receptor, in contrast, show a subtle (20-32\%) but persistent reduction of NURR1-positive mDA precursors and TH-positive mDA neurons [183], suggesting that this receptor might also participate in the transduction of a "canonical" WNT/ $\beta$-catenin signal.

Most of the mouse mutants mentioned above have the caveat of very early and extensive deficits affecting the development of the entire midbrain region and thus potentially masking more specific and/or subtle defects in mDA neuron generation. Therefore, analyses of mouse mutants with no obvious developmental phenotype provided the first indication that a dose-dependent $\mathrm{WNT} / \beta$-catenin signaling is implicated, in particular, in the subset-specific differentiation of mDA neurons. Dkk3 is a divergent member of the DKK family of WNT inhibitors expressed in the midline of the VM (medial FP) [184], whose precise function in WNT/ $\beta$-catenin signaling remains debated [185]. Dkk3 null mutant mice show a subtle but clear mDA phenotype: a consistent reduction by approx. a fifth (20\%) of a TH- and PITX3-positive mDA neuron subset located in the dorsomedial SNc and parabrachial pigmented nucleus (PBP, a part of the VTA) from E12.5 on, and an initially corresponding increase of TH-positive but PITX3-negative cells and later (at E18.5) loss of these and of TH-negative/PITX3-positive cells in this brain region [184]. These deficits are not accompanied by any patterning, proliferation, or specification defects in the $D k k 3$ null VM [184], strongly suggesting that the lack of DKK3 and concomitantly of an attenuation of WNT/ $\beta$-catenin signaling in the medial FP specifically affects the differentiation of a rostrolateral mDA neuronal subset that might be considered the murine equivalent of the human SNc [186]. Generation of the more caudally located VTA DA neurons, probably exposed to higher levels of $\mathrm{WNT} / \beta$-catenin signaling along the $\mathrm{A} / \mathrm{P}$ axis of the murine VM [187], is in fact more affected in the conditional $\beta$-catenin LOF mutants $[135,163,172]$, whereas the generation of the rostrolateral SNc DA neurons is more affected in the conditional $\beta$-catenin GOF mutant mice $[135,170,171,173]$. Consistent with this idea, the extent and size of the mDA progenitor and mature neuron population in the embryonic mouse VM is also modulated by miR-135a2, a microRNA (miRNA) that targets the homeodomain TF Lmx1b upstream of the WNT1/ $\beta$-catenin signaling pathway [188].

Altogether, the in vivo data revealed that "canonical" WNT/ $\beta$-catenin signaling, prominently activated by the WNT1 molecule that is expressed at the MHB and in the VM, plays a pivotal role during the entire span of mDA neuron development: from the early establishment (patterning) of the mDA progenitor domain in the mammalian VM (not discussed here, see Reference [18]), the intermediate specification of the mDA cell fate in mitotic and postmitotic VM neural precursors, to their later differentiation into mature mDA neurons. Furthermore, they also indicated that a precise 
and potentially mDA neuron subset-specific balance of the strength of $\mathrm{WNT} / \beta$-catenin signaling appears to be crucial for the proper generation of $\mathrm{mDA}$ neurons in general and of subset-specific (e.g., SNc or VTA) mDA neurons in particular. The "non-canonical" WNT/PCP pathway, in turn, is implicated in the proper morphogenesis of the entire midbrain region, including the establishment of cell polarity and the correct migration and neurite extension within the mDA domain.

2.3.3. WNT Signaling in the Directed Differentiation of PSCs and Direct Conversion of Somatic Cells into mDA Neurons In Vitro

In contrast to the rodent or human embryo in vivo, primary VM or PSC cultures in vitro offer the significant advantage of being easily accessible and manipulable. Initial experiments using rodent primary neuroectodermal tissues (neural plate explant cultures) or VM NSCs showed that Wnt1 is required to induce ectopic mDA neurons even if FGF8 and SHH, two other essential morphogens for mDA neuron induction [66] (Sections 2.1 and 2.2), are present, and that WNT1 protein or conditioned media promote the generation of TH-positive mDA neurons $[135,152,153]$. Conversely, the silencing of Wnt1 expression in differentiating human multipotent NSCs results in lower yields of TH-positive neurons [189]. Later experiments revealed a ligand- and dose-dependent action of WNT signaling on the differentiation of mDA neurons from rodent and human NSCs or mouse PSCs, whereas treatment of the differentiating cells with WNT5A or other WNT/PCP signaling agonists (such as SFRP1/2) generally increases the yield of TH-positive mDA neurons, addition of WNT1 or of WNT / $\beta$-catenin agonists (such as the small molecule GSK3 $\beta$ inhibitors CHIR/CT99021 and kenpaullone, [190]) promotes the generation of TH-positive mDA neurons at low dosage but inhibits it at high dosage, thus confirming the previous in vivo data also in vitro [164,173,191-194]. Because the derivation of functional and pure (without other contaminating neuronal cell types) $\mathrm{mDA}$ neurons turned out to be much more difficult to be achieved from primate and human PSCs, a major breakthrough was the discovery that these PSCs are efficiently differentiated into functional mDA neurons by a protocol that uses the "dual SMAD" inhibitors to suppress alternative mesodermal and endodermal cell fates, and a high dose of SHH or SHH agonists and of the GSK3 $\beta$ inhibitor CHIR99021 in the presence of FGF8 to induce mDA precursors ([43]; reviewed in References $[155,156])$. However, other groups subsequently noted a concentration- and time-dependent action of WNT/ $\beta$-catenin pathway activation (i.e., GSK3 $\beta$ inhibition by the CHIR/CT99021 compound) in human and primate PSCs, whereas low CHIR/CT99021 concentrations (i.e., low WNT/ $\beta$-catenin signaling levels) and/or late application of this compound induces forebrain neurons expressing typical markers for this brain region, high CHIR/CT99021 concentrations (i.e., high WNT/ $\beta$-catenin signaling levels), and early application of this molecule generates neurons with a hindbrain identity, and only the early application of intermediate CHIR/CT99021 concentrations (i.e., intermediate WNT / $\beta$-catenin signaling levels) is capable of inducing genuine $\mathrm{mDA}$ neurons that can functionally restore movement deficits in rodent PD models $[150,195]$. Indeed, recent findings showed that only a precisely titrated and timed addition of the key factors (FGF8, SHH, and a WNT/ $\beta$-catenin activator/GSK3 $\beta$ inhibitor) for mDA neuron induction from rodent or human NSCs and PSCs during the differentiation procedure is capable of generating fully functional grafts with an authentic mDA neuron identity and without contaminating rostral (forebrain/hypothalamic) or caudal (hindbrain) cells $[76,97,196]$. Gaucher's Disease patients carrying mutations in the acid beta-glucocerebrosidase (GBA1) gene have a high risk for PD [197], and restitution of the normal WNT/ $\beta$-catenin signaling levels in human iPSCs derived from these patients (in which this signaling pathway appears to be affected) by CHIR99021 application also improves the generation of mDA neurons from these cells [198]. In agreement with the above-mentioned in vivo data, the appropriate WNT1/ $\beta$-catenin signaling levels for ensuring the efficient and correct differentiation of mDA neurons from naïve and "primed" (epiblast-derived stem cells) PSCs appear to be regulated by another miRNA, $m i R-34 b / c$ [199]. Notably, overexpression of this miRNA also facilitates the direct conversion (so-called "reprogramming" or transdifferentiation) of mouse embryonic fibroblasts (MEFs) into DA-secreting and spontaneously firing induced DA 
(iDA) neurons, whereas the simultaneous overstimulation of the WNT/ $\beta$-catenin pathway with the GSK3 $\beta$ inhibitor CHIR99021 suppresses this process [199]. In other contexts, however, application of intermediate CHIR/CT99021 concentrations (i.e., intermediate WNT/ $\beta$-catenin signaling levels) promotes the direct conversion of MEFs and adult mouse tail tip fibroblasts or human astrocytes into iDA neurons with a typical mDA marker expression and electrophysiological properties using either the four Yamanaka pluripotency TFs Oct4 (Pouff1), Sox2, Klf4, and c-Myc [200], or the mDA-specific factors Neurod1, Ascl1 (Mash1), Lmx1a, and miR-218 [201]. Altogether, these in vitro data indicate that a precise dosage and timing of $\mathrm{WNT} / \beta$-catenin signaling activation in rodent and primate (including human) PSCs or somatic cells facilitates their differentiation into DA neurons with molecular and physiological characteristics of genuine mDA neurons in vivo and capable of restoring the motor function in animal models of PD.

Most of these protocols did not focus on the generation of specific mDA neuron subsets, although several authors reported that at least part of the generated mDA neurons express molecular markers and/or electrophysiological properties of the rostrolateral SNc DA neurons [43,195,199-201]. Using a very similar differentiation protocol as Kriks et al. [43], the combined treatment of differentiating mouse PSCs with WNT1 and DKK3 proteins instead of the potent GSK3 $\beta$ inhibitor CHIR99021 increases the overall proportion of TH-, NURR1-, and PITX3-positive mDA neurons in these cultures [184]. Notably, the differentiating PSCs preferentially adopt a molecular identity of rostrolateral SNc DA neurons expressing KCND3 but not calbindin 1 (CALB1) under these conditions [184]. The expression of the A-type voltage-gated potassium channel subunit KCND3 (Kv4.3) is restricted to SNc DA neurons in the adult rodent VM [202,203], whereas the calcium-binding protein CALB1 (CalbindinD28K) is expressed prominently but not exclusively in VTA DA neurons $[8,204]$. Despite the still unclear function of DKK3 in the WNT / $\beta$-catenin signaling pathway [185], transcriptome profiling of the differentiated PITX3-positive cells strongly suggested that DKK3 attenuates $\beta$-catenin-mediated WNT1 signaling to enable the proper generation of rostrolateral (dorsomedial SNc and PBP) mDA neurons, which are selectively affected in the corresponding mouse mutants [184]. Collectively, these data suggest that a fine-tuned activation or attenuation of WNT1/ $\beta$-catenin signaling might even enforce the generation of a particular mDA neuron subset, VTA or SNc, from murine and human PSCs or somatic cells.

\subsection{BMP Signaling in Midbrain Dopaminergic Neuron Generation In Vivo and In Vitro}

\subsubsection{The BMP Signaling Pathway}

BMPs are part of the TGF $\beta$ protein superfamily. The TGF $\beta$ family members are subdivided into two groups: the BMP group that includes all BMPs and most growth and differentiation factors (GDFs) and the TGF $\beta$ group that comprises the three mammalian TGF $\beta$ isoforms (TGF $\beta 1-3$ ), activins, nodals, and some GDFs.

BMPs were first identified as proteins that induce ectopic bone formation, hence their name [205]. BMPs regulate a wide array of neurodevelopmental processes, including progenitor proliferation, apoptosis, and differentiation [206-208]. Depending on the cell type, extracellular environment and developmental stage, they might enhance or inhibit these processes. Over a dozen BMPs have been identified in vertebrates so far [205]. BMP family members can be classified into several subgroups according to their structural similarities. These subgroups include the BMP2/4 group, BMP5/6/7 (OP1)/8 group, BMP9/10 group, and BMP12/13/14 group [205]. Specifically, the two subgroups which were named after their Drosophila orthologs, the decapentaplegic (DPP) subgroup (BMP2 and BMP4), and the 60A subgroup (BMP5, BMP6, BMP7, and BMP8), are expressed in the mammalian nervous system [209,210], with the exception of BMP8, which is not expressed in the brain [211].

BMPs are secreted proteins that bind to BMP receptors (BMPRs) as homodimers or heterodimers. The heteromeric BMPR complexes contain type I and type II serine-threonine kinase receptor subunits (Figure 2). BMPs are capable of binding to type I receptors in the absence of type II receptors. However, the presence of type I and type II receptors significantly increase the binding affinities of BMPs [205,212]. 
The type II receptors phosphorylate and thereby activate the type I receptors, which transduce the BMP signal. In mammals, three type II receptors mediate the activity of BMPs: the BMP type II receptor (BMPRII), the activin type II receptor (ACTRII), and the activin type IIB receptor (ACTRIIB). In contrast to BMPRII, which is specific for BMPs, ACTRII and ACTRIIB are activated by BMPs, activins, and myostatin [205,212]. The activin receptor-like kinases (ALK) 1, 2, 3 (BMPRIA), and 6 (BMPRIB) serve as type I receptors for most BMPs. In addition to ligand-receptor specificity, BMP signaling can be further regulated extracellularly by direct interaction of BMPs with their secreted antagonists such as noggin (NOG) (Figure 2) [205].

The canonical BMP signaling pathway is activated by binding of BMPs to BMPRs and mediated by SMADs (Figure 2). Activated type I receptors signal by phosphorylating the receptor-regulated SMADs (R-SMADs), SMAD1, SMAD5, and SMAD8, which can then bind the co-regulated SMAD4 (coSMAD). The R-SMAD/coSMAD complexes translocate and accumulate in the nucleus, where they act as TFs and participate in the regulation of target gene expression [213] (Figure 2). Phosphorylated SMAD1, 5, and 8 are the major intracellular BMP signaling pathway components. BMPs also activate SMAD-independent signaling pathways such as MAPKs, JNK, PI3K, AKT, and small GTPases [205,214]. These non-canonical pathways cooperate with SMAD pathways to regulate various cellular responses. In contrast to the BMP group members, TGF $\beta$ group members bind to TGF $\beta$ and activin type II receptors and use predominantly ALK4, 5, and 7 as type I receptors, which signal via SMAD2 and SMAD3 [213].

\subsubsection{The Function of the BMP Signaling Pathway in the Generation of Mammalian mDA Neurons In Vivo}

In contrast to WNTs, FGFs, and SHH, the essential role of BMPs in the formation of mammalian mDA neurons in vivo has only been discovered recently [19]. The first indication that BMP signaling could be involved in the generation of mammalian $\mathrm{mDA}$ neurons in vivo came from in vitro studies [215,216] and expression studies in mice [19]. Before the onset of mDA neurogenesis at E10.5, BMP5, BMP6, and BMP7, as well as phosphorylated SMAD1/5/8 (pSMAD1/5/8), are expressed in the $\mathrm{VM}$ close to and within the mDA progenitor domain. The BMP receptor 1B (BMPR1B), which plays a critical role in neuronal differentiation [217], is confined to the mDA domain around the peak of mDA neurogenesis at E12.5 [19].

To assess the function of BMP signaling in the development of mDA neurons, the formation of these cells were analyzed in different Bmp single and compound LOF mouse mutants [19]. Changes were not apparent in the generation of mDA neurons in Bmp5, Bmp6, and Bmp7 single-null mutants, nor in Bmp5/Bmp6 and Bmp6/Bmp7 double-null mutants. In Bmp5/Bmp7 double-null mutants, however, postmitotic mDA neurons, expressing NURR1 and the pan-neuronal marker $\beta I I I$ tubulin (TUJ1, Tubb3), were entirely absent at E10.5, the latest developmental time point mutants can be studied before they die of cardiac malformations. Different mechanisms are used by BMP5/7 to control the generation of mDA neurons. First, BMP5/7 regulate the proliferation of the mDA progenitor population. Second, BMP5/7 promote mDA neurogenesis by regulating MSX1/2 and NGN2 expression. In contrast to the mDA progenitor domain within the FP, BMP5/ 7 appear to prevent the premature neurogenesis in the adjacent midbrain BP. As discussed below, these differences can be explained by the expression of SHH in the FP, which is under the regulatory control of BMP5/7.

Based on the lack of postmitotic mDA neurons and the downregulation of pSMAD1/5/8 in Bmp5/Bmp7 double null mutants, it was hypothesized that components of the SMAD signaling pathway are mediating aspects of the effect of BMP5/7 on mDA neuron generation [19]. To test this hypothesis, the formation of mDA neurons was assessed in mutants in which Smad1 was conditionally inactivated starting from approximately E10-11 using a Nestin-Cre driver [218]. Consistent with a role in mediating the effects of BMPs on mDA generation, the conditional inactivation of Smad1 in mouse NSCs in vivo leads to a significant reduction of mDA neurons. Although Bmp5/Bmp7 double null mutants show a decrease in $\mathrm{mDA}$ progenitor cell proliferation at E10.5, conditional Smad1 mutants show an increase at E12.5. The downregulation of pSMAD1/5/8 and the unaltered expression of 
the non-canonical BMP pathway in Bmp5/Bmp7 double null mutants suggest that the differences in cell proliferation are unlikely to be caused by disruptions of different signaling pathways. Instead, the different phenotypes might be explained by the different time points when the consequences of $\mathrm{Bmp} /$ Smad inactivation were studied. This suggests a distinct response of forming $\mathrm{mDA}$ neurons to the BMP/SMAD pathway at different stages of their development.

Evidence that the BMP receptors BMPR1A and BMPR1B have sequential roles during development might explain the phenotypic differences between $B m p 5 / B m p 7$ double null and conditional Smad1 mutants [217]. BMPR1A is ubiquitously expressed in NSCs from early development onward and regulates the proliferation of these cells. In contrast, BMPR1B starts to be expressed only later during embryogenesis, causing mitotic arrest and terminal differentiation [217]. At the onset of mDA neurogenesis at E10.5, the reduced BMPR1A/SMAD activation in Bmp5/Bmp7 double null mutants is responsible for the reduced cell proliferation. During later stages (at E12.5), when SMAD1 mediates the differentiating effects of BMPR1B, whose expression is confined to the mDA progenitor domain in the VM [19], loss of this signaling component attenuates the cell cycle exit and differentiation of mDA neurons.

Interestingly, TH-/SOX6-positive and TH-/GIRK2-positive SNc DA neurons were especially reduced in the conditional Smad1 mutants [19]. In contrast, the red nucleus neurons developed normally in the BP of these mutants. Further experiments studying the molecular underpinnings of this specific vulnerability of SNc DA neurons to reduced or absent BMP signaling are expected to provide important information for the better understanding of the specific degeneration of SNc DA neurons in PD.

\subsubsection{BMPs in Stem Cell-Derived mDA Neuron Maturation}

Current protocols for the derivation of mDA neurons from mammalian PSCs are based on the activation of the FGF, SHH, and WNT signaling pathways, which regulate the generation of mammalian mDA neurons in vivo [12,42-44]. In contrast, the potential of BMPs in the differentiation of PSCs to mDA neurons has not been investigated extensively and the few publications did not yield consistent conclusions so far. Thus, early exposure to BMP4 in a protocol for mDA neuron differentiation from human ESCs results in a significant reduction of DA neurons [219]. In contrast, early addition of BMP2, together with SHH and FGF8, promotes the differentiation of mDA neurons by modulating the SHH gradient and increasing the expression of LMX1A and FOXA2 in human PSCs [220]. More recently, BMP7, together with pramipexole, have been reported to increase the yield of DA neurons differentiated from forebrain-derived human NSCs [221].

A significant progress in the directed neural differentiation of human PSCs was the discovery that blocking the BMP/TGF $\beta$ ("dual SMAD") signaling pathway during the initial steps of the protocol leads to a highly efficient neural conversion [42-44]. However, the role of BMPs during the later stages of $\mathrm{mDA}$ specification and maturation in vitro remained unclear. To address this issue, the potential of BMP5/7 was studied in the directed differentiation of mDA neurons from two independent human iPSC lines and a previously established induced NSC (iNSC) line [222-225]. For this purpose, a widely used mDA differentiation protocol was modified that includes the activation of the FGF8 and SHH signaling pathways [226]. BMP5/7 treatment during the 22 days of the maturation phase resulted in a strong increase in the numbers of TH-positive neurons derived from both human iPSC lines and iNSC cultures [19]. Conversely, the requirement of BMP5/7 for the generation of mDA neurons was tested by blocking the BMP signaling pathway using NOG in two independent human iPSC lines during the maturation phase. The number of TH- and TUJ1-positive mDA neurons is significantly reduced after NOG treatment in both cultures, indicating a blockade of mDA neuron generation [19]. Taken together, these data indicate that BMP5 together with BMP7 robustly promote the maturation of PSCs and NSCs into mDA neurons, and that activation of the BMP signaling pathway during the maturation phase is an essential part of currently used protocols for the generation of mDA neurons from mammalian PSCs. 
2.5. Cross-Talk between the FGF, SHH, WNT, and BMP/TGF $\beta$ Signaling Pathways in Midbrain Dopaminergic Neuron Generation In Vivo and In Vitro

\subsubsection{Crosstalk between FGF/FGF8 and WNT Pathways}

FGF and WNT signaling pathways interact during early midbrain development to establish and maintain the activity of the IsO. Experiments both in vivo and in vitro have shown that the two signaling molecules regulate the expression of each other, resulting in the complementary patterns of Fgf8 and Wnt1 expression on the opposite sides of the MHB [227-231]. The expression of Fgf8 is lost when WNT1 signaling is inactivated and, conversely, ectopic WNT stimulation or activation of the $\beta$-catenin mediated "canonical" WNT signaling pathway can increase $F g f 8$ expression. Interestingly, stabilization of $\beta$-catenin results in $F g f 8$ upregulation in the anterior hindbrain (rhombomere 1), but not in the midbrain, demonstrating different competence of these brain regions and providing a partial explanation for the complementary expression patterns $[169,230,231]$. On the other hand, FGF signaling is also thought to maintain, rather than induce, Wnt1 expression in the posterior midbrain [232]. Although not completely understood, these cross-regulatory mechanisms may include direct or indirect transcriptional control by the signal-dependent TFs. The latter may involve downstream TFs like EN1 [233-236].

In contrast to the $\mathrm{IsO}$, where the expression of Wnt1 and Fof8 genes depend on each other, Wnt1 expression is independent of FGF signaling in the mouse VM, which gives rise to the mDA neurons [57]. The Wnt1 gene may thus have distinct regulatory elements driving expression in the IsO and the VM tissue. This also suggests that the effects of FGF signaling on the mDA progenitors are not due to changes in local Wnt1 transcription. However, there are other, yet incompletely understood, possibilities for interaction of the FGF and WNT signaling pathways. For example, FGF signaling was recently shown to regulate the translational efficiency of several WNT signaling pathway components in mammary epithelial cells [237]. In addition, regulation of SPRY4, a negative feedback regulator of the RAS-MAPK (mitogen-activated protein kinases) pathway, was suggested to be regulated by both FGF and WNT signaling in the zebrafish dorsal midbrain [231]. Similar cross-regulation of feedback antagonists of WNT and FGF signaling pathways has been observed in the zebrafish lateral line [238]. Studies in other developmental contexts have demonstrated multiple interactions between the signaling cascades downstream of the FGF and WNT receptors, with effects on $\beta$-catenin activity, $\mathrm{Ca}^{2+}$ signaling, and the cytoskeleton [239]. How such mechanisms operate in the developing mDA neuron progenitors remains unknown.

\subsubsection{Crosstalk between SHH and WNT Pathways}

As described above, the combined activation of WNT and SHH signaling is crucial for the induction of authentic mDA neurons from human PSCs. Studies on the spinal cord have uncovered some of the molecular mechanisms that could account for the intersection between WNT and SHH signaling $[240,241]$. In mDA progenitor induction and neurogenesis, LOF and GOF studies in mice provide evidence for the interaction between these two signaling pathways.

Conditional inactivation of Smo using Shh-Cre results in a subtle increase in Wht1 expression, while constitutive activation of SHH signaling in Shh-expressing cells leads to a slight reduction in Wnt1 expression [124] (Figure 2). In contrast, the loss of primary cilia in Ift88 cKO mutants and the concomitant inactivation of SHH signaling results in reduced expression of Wnt1 and Wnt5a and a reduced expression of the WNT signaling readout Axin2 [142]. An explanation for the discrepancy in the phenotype between mice lacking primary cilia and mice with inactivated Smo might be the time point of inactivation, the spatial extent of inactivation (the entire midbrain or just the FP, respectively), or a direct effect of primary cilia loss on Wnt expression and signaling [242]. Thus, while these results suggest that $\mathrm{SHH}$ signaling regulates Wnt expression in the VM, the precise effect of SHH on Wnt expression levels remains to be explored. 
On the other hand, WNT signaling regulates Shh expression in the mDA progenitor domain. The downregulation of Shh in the ventral midline that is normally observed in this domain at E11.5 does not occur when WNT signaling is abolished in the FP by inactivating $\beta$-catenin (Ctnnb1) in Shh-expressing progenitors. In the converse experiment, the expression of a stabilized $\beta$-catenin in the Shh-expressing population, Shh expression is downregulated in the midbrain FP [135,171] (Figure 2). Moreover, high doses of SHH and WNT antagonize each other's ability to induce mDA cell fates, both in cultures of VM progenitors and during the induction of mDA neurons from ESCs [173]. Based on these results, it has been proposed that WNT signaling promotes neurogenesis through the downregulation of Shh in the mDA progenitor domain $[135,173]$. Still, SHH signaling itself plays only a minor, transient role in regulating the proliferation and neurogenesis of the mDA progenitors [122,124]. A more recent study dissected the effect of WNT upregulation on mDA neuron development in further detail, demonstrating that activated WNT signaling does not only downregulate expression of Shh, but also of Foxa2 and $L m x 1 b$. Ventral midline progenitors adopt a mixed identity, expressing factors characteristic for mDA progenitors (LMX1A/B) along with factors characteristic for red nucleus progenitors (NKX6-1 and NEUROG1). These NEUROG1-expressing progenitors give rise to neurons with features typical of the red nucleus, at the expense of mDA neurons [171]. Thus, while it is clear that WNT regulates Shh expression (directly or indirectly), the functional consequence on mDA neuron development in vivo is likely mediated by a more general role of WNT signaling in determining $\mathrm{mDA}$ progenitor fate.

\subsubsection{Crosstalk between WNT and BMP/TGF $\beta$ Pathways}

Another potential but only rudimentarily explored crosstalk in mDA neuron development is the interaction between the WNT and BMP/TGF $\beta$ signaling pathways. First hints towards such a crosstalk during the in vitro generation of mDA neurons from human PSCs came from a systematic study about the effects of the "dual SMAD" (BMP and TGF $\beta$ ) inhibitors, now widely used in the human PSC differentiation protocols for mDA neurons [243]. The authors of this study concluded that inhibitors of the BMP/SMAD1, 5, 8 signaling pathway in particular, or the combined treatment with BMP and TGF $\beta$ /SMAD2, 3 inhibitors, increase indirectly the expression of $W n t 1$ and $W N T / \beta$-catenin signaling through the induction of the Zinc finger E-box binding homeobox 2 (ZEB2 and SIP1) TF, which in turn represses the gene encoding the WNT inhibitor Sfrp1 [243]. However, they also noted that the efficient generation of authentic mDA neurons requires the presence of potent SHH agonists (probably because of the strong repression of Shh by the increased WNT/ $\beta$-catenin signaling, see Section 2.5.2) and of FGF8 in these cultures, and that the administration of the potent GSK3 $\beta$ inhibitor CHIR99021 might not be necessary if the combined BMP/TGF $\beta$ inhibitor levels are sufficiently high to induce a strong enough WNT/ $\beta$-catenin signal in this protocol [243]. Altogether, their data suggested that $\mathrm{WNT} / \beta$-catenin signaling is antagonized by the BMP/TGF $\beta$ pathway during $\mathrm{mDA}$ neuron generation in vitro. This finding is in line with previous observations in the dorsal midbrain of conditional TGF $\beta$ type II receptor (Tgfbr2) mouse mutants [244]. Based on the unaltered expression and distribution of Wnt $1 \mathrm{mRNA}$ and $\beta$-catenin protein in the VM of Bmp5/Bmp7 double null and conditional Smad1 mutants, no obvious evidence for a crosstalk between the BMP/SMAD1 and WNT1/ $\beta$-catenin signaling pathways was found during mouse mDA neuron development in vivo [19]. However, the significantly reduced levels of phosphorylated (destabilized) $\beta$-catenin in the VM of the $B m p 5 / B m p 7$ double null mutants might hint at a corresponding increase of unphosphorylated (stabilized) $\beta$-catenin levels and thus activation of the $W N T / \beta$-catenin signaling pathway in the absence of BMP5/7 [19]. Because this interpretation would be at odds with the observed increase of $\mathrm{SHH}$ expression and reduced proliferation and neurogenesis of $\mathrm{mDA}$ progenitors in the $\mathrm{Bmp} 5 / \mathrm{Bmp} 7$ double-null mutant VM [19], further experiments are warranted to clarify this issue.

Perhaps the most intriguing clue so far for a potential crosstalk between the $\mathrm{WNT} / \beta$-catenin and BMP/TGF $\beta$ signaling pathways in $\mathrm{mDA}$ neuron development is provided by the previous finding that DKK3, a putative inhibitor or at least attenuator of $\mathrm{WNT} / \beta$-catenin signaling in 
different tissue contexts [245], not only promotes the proper differentiation of a rostrolateral mDA neuron subset, but also their later survival in the mouse VM and in the culture dish $[184,246]$. During development (both in vivo and in vitro) and in a genetic mouse model of PD (the heterozygous En1 mouse, [247]), this is at least partly due to the downstream induction or maintenance, respectively, of a WNT1/ $\beta$-catenin-driven neuroprotective gene cascade comprising the TFs Lef1, Lmx1a, and Pitx3, and the neurotrophic factors Bdnf, Fgf20, and Dkk3 [184,246,248-250] (Figure 2). More recent and yet unpublished findings, however, indicate that only very few $\mathrm{WNT} / \beta$-catenin-responsive $\mathrm{mDA}$ neurons are detected within the rostrolateral SNc region at late developmental and adult stages in the mouse, as opposed to the caudomedial VTA DA region, where numerous WNT/ $\beta$-catenin-responsive mDA neurons reside at these stages [251]. This raises the possibility that DKK3 acts via a completely distinct pathway in this context, namely TGF $\beta$ /SMAD signaling, which has been widely implicated in the survival and neuroprotection of developing and mature mDA neurons in the mammalian brain (reviewed in Reference [252]). Because DKK3 can both synergize with and antagonize the TGF $\beta$ /SMAD signaling pathway in different cell and tissue contexts [253-256], the precise mechanism of DKK3 action during mDA neuron development and adult survival remains elusive. Based on the current evidence, however, DKK3 might activate or maintain TGF $\beta$ /SMAD signaling in medial FP $\mathrm{mDA}$ progenitors and maturing rostrolateral (dorsomedial SNc and $\mathrm{PBP}$ ) $\mathrm{mDA}$ neurons. Moreover, because the LOF of SMAD1 in conditional Smad1 mutants also affects preferentially the differentiation of rostrolateral (SNc) SOX6- and GIRK2-positive mDA neurons [19], DKK3 might even synergize with SMAD1-mediated BMP signaling in this context. A better understanding of the generation of this particular mDA neuron subset during embryonic development, especially in view of more efficient and consistent PSC differentiation protocols for this mDA neuron subtype, still awaits clarification of these points.

\subsubsection{Crosstalk between BMP and SHH Pathways}

Since BMPs were only recently identified to play an essential role in the generation of mammalian mDA neurons in vivo, only little is known about the interaction of BMP signaling with other pathways. During the studies of the requirement of BMP5/7 and SMAD1 for the development of mDA neurons, the interactions of the BMP signaling pathway with the WNT and SHH signaling pathways were investigated. To do this, the expression of WNT and SHH signaling components were analyzed in Bmp5/Bmp7 double null mutants.

Neither Wnt1 mRNA nor total $\beta$-catenin protein expression, which plays a critical role in mediating "canonical" WNT/ $\beta$-catenin signaling, are altered in Bmp5/Bmp7 double null mutants [19]. Moreover, cell adhesion, which is dependent on intact $\beta$-catenin in the mDA progenitor domain [172,174], is unperturbed in the double null mutants as assessed by the normal expression of $\mathrm{N}$-cadherin and $\mathrm{ZO1}$ [19]. In contrast, the expression of $\mathrm{SHH}$, measured as a ratio between the $\mathrm{SHH}$ immunoreactivity in the midline and the $\mathrm{SHH}$ signal in a region outside of the $\mathrm{SHH}$ expression domain, is nearly doubled in the Bmp5/Bmp7 double null mutants [19].

There are many examples for a close interaction between the SHH, WNT, and BMP signaling pathways in the generation of non-mDA neuronal populations [257]. Thus, an interaction of all three signaling pathways might provide the permissive environment necessary for mDA neurogenesis. Starting at around E8.0, SHH signaling is important for the formation of the SHH-/FOXA2-positive FP and mDA progenitor domain $[66,120,125]$. However, at the onset of mDA neurogenesis, SHH was suggested to inhibit FP mDA neurogenesis [135]. The WNT/ $\beta$-catenin pathway is necessary and sufficient for the restriction of SHH expression. Based on this observation it was suggested that this WNT/SHH interaction creates a permissive environment for mDA neurogenesis $[135,172,173]$. The upregulation of SHH expression and the concomitant reduced mDA progenitor proliferation and neurogenesis in the $B m p 5 / B m p 7$ double-null mutants therefore indicates that the restriction of SHH availability by BMPs might provide one mechanism by which BMPs control mDA neurogenesis. The property of BMP7 to reduce SHH expression is not limited to the midbrain, as demonstrated by 
ectopic expression of BMP7 in the hindbrain. Misexpression of BMP7 in this brain region, where it is normally not expressed, attenuates the expression of SHH in the FP [258]. Taken together, these data suggest that one of the functions of the BMP5/7 signaling pathway in the development of mDA neurons is to create a permissive environment for mDA neurogenesis by restricting the expression of $\mathrm{SHH}$ in the midbrain FP.

\section{Conclusions}

In this review, we have summarized the current knowledge on the role of the four major signaling pathways and their known or putative interactions regulating the generation of $\mathrm{mDA}$ neurons in vivo and in vitro (Table 1). Despite substantial advances in recent years, we are only at the beginning of understanding how the crosstalk between these four prominent signaling pathways orchestrates the development of mDA neurons in the mammalian embryo, and how we can use this knowledge to generate stem cell-derived and subtype-specific mDA neurons.

Many open questions still remain regarding the in vivo and in vitro generation of mammalian mDA neurons and will continue to make it an exciting research field, but the two most pressing are: (1) Which molecular mechanisms underlie the specification of SNc DA neurons versus VTA DA neurons in vivo? This question is of particular interest, as it can be expected that the answer will provide direct insights into the specific vulnerability of SNc DA neurons in PD. (2) What will be the results of the very recently initiated clinical trials using human stem cell-derived mDA neurons for cell replacement therapy? Efficacy and safety outcomes of these trials will have a major impact for the direction of future research. Tailoring essential parameters of cell grafts including the degree of differentiation, cellular composition, and survival rates will require also in the future a close interaction between basic and clinical research.

Table 1. Functions and crosstalk of the four main signaling pathways in mDA neuron generation.

\begin{tabular}{ccccc}
\hline & FGFs & SHH & WNTs & BMPs \\
\hline VM patterning & Yes & Yes & Yes & No $^{1}$ \\
\hline Progenitor proliferation & Yes & Yes & Yes & Yes \\
\hline Subtype specification & Yes? $^{2}$ & Yes & Yes? ${ }^{2}$ & Yes \\
\hline Differentiation & Yes & No & Yes & Yes \\
\hline Survival & Yes & No & Yes & N.D. $^{3}$ \\
\hline $\begin{array}{c}\text { In vitro stem/somatic } \\
\text { cell differentiation }\end{array}$ & $\begin{array}{c}\text { Mouse and human } \\
\text { ESCs, iPSCs, iDA }\end{array}$ & $\begin{array}{c}\text { Mouse and human } \\
\text { ESCs, iPSCs, iNSC }\end{array}$ & $\begin{array}{c}\text { Mouse and human ESCs, } \\
\text { iPSCs, iDA }\end{array}$ & Human iPSCs, $_{\text {Human iNSC }}$ \\
\hline $\begin{array}{c}\text { Known pathway } \\
\text { interaction }\end{array}$ & $\begin{array}{c}\text { Promotes Wnt1 } \\
\text { expression }\end{array}$ & $\begin{array}{c}\text { Regulates Wnt } \\
\text { expression }\end{array}$ & $\begin{array}{c}\text { Represses Shh, promotes } \\
\text { Fgf8 expression }\end{array}$ & $\begin{array}{c}\text { Represses SHH } \\
\text { expression }\end{array}$ \\
\hline
\end{tabular}

${ }^{1}$ VM patterning has only been assessed for BMP5/6/7. ${ }^{2}$ Final evidence is still missing. ${ }^{3}$ Not determined.

Author Contributions: C.B., S.B., J.P. and N.P. contributed equally and wrote the paper together.

Funding: Our work was supported by the Israeli Science Foundation (grant 1391/11) to CB and The United States-Israel Binational Science Foundation (grant 2015356) to CB; and by the Deutsche Forschungsgemeinschaft (DFG, German Research Foundation)-BL 767/2-1, BL 767/3-1 and Projektnummer 417960915 to SB, and Projektnummer 408031320 to NP.

Conflicts of Interest: The authors declare no conflict of interest. The founding sponsors had no role in the writing of the manuscript, or in the decision to publish it.

\section{References}

1. Bjorklund, A.; Dunnett, S.B. Dopamine neuron systems in the brain: An update. Trends Neurosci. 2007, 30, 194-202. [CrossRef] [PubMed]

2. Ranganath, A.; Jacob, S.N. Doping the Mind: Dopaminergic Modulation of Prefrontal Cortical Cognition. Neuroscientist 2016, 22, 593-603. [CrossRef] [PubMed] 
3. Grace, A.A. Dysregulation of the dopamine system in the pathophysiology of schizophrenia and depression. Nat. Rev. Neurosci. 2016, 17, 524-532. [CrossRef] [PubMed]

4. Hadley, J.A.; Nenert, R.; Kraguljac, N.V.; Bolding, M.S.; White, D.M.; Skidmore, F.M.; Visscher, K.M.; Lahti, A.C. Ventral tegmental area/midbrain functional connectivity and response to antipsychotic medication in schizophrenia. Neuropsychopharmacology 2014, 39, 1020-1030. [CrossRef]

5. Bodea, G.O.; Blaess, S. Establishing diversity in the dopaminergic system. FEBS Lett. 2015, 589, 3773-3785. [CrossRef] [PubMed]

6. Morello, F.; Partanen, J. Diversity and development of local inhibitory and excitatory neurons associated with dopaminergic nuclei. FEBS Lett. 2015, 589, 3693-3701. [CrossRef] [PubMed]

7. Anderegg, A.; Poulin, J.-F.; Awatramani, R. Molecular heterogeneity of midbrain dopaminergic neurons-Moving toward single cell resolution. FEBS Lett. 2015, 589, 3714-3726. [CrossRef]

8. Fu, Y.; Yuan, Y.; Halliday, G.; Rusznak, Z.; Watson, C.; Paxinos, G. A cytoarchitectonic and chemoarchitectonic analysis of the dopamine cell groups in the substantia nigra, ventral tegmental area, and retrorubral field in the mouse. Brain Struct. Funct. 2012, 217, 591-612. [CrossRef]

9. Blaess, S.; Ang, S.-L. Genetic control of midbrain dopaminergic neuron development. Wiley Interdiscip. Rev. Dev. Biol. 2015, 4, 113-134. [CrossRef]

10. Roeper, J. Dissecting the diversity of midbrain dopamine neurons. Trends Neurosci. 2013, 36, 336-342. [CrossRef]

11. Brignani, S.; Pasterkamp, R.J. Neuronal Subset-Specific Migration and Axonal Wiring Mechanisms in the Developing Midbrain Dopamine System. Front. Neuroanat. 2017, 11, 55. [CrossRef] [PubMed]

12. Arenas, E.; Denham, M.; Villaescusa, J.C. How to make a midbrain dopaminergic neuron. Development 2015, 142, 1918-1936. [CrossRef] [PubMed]

13. Prakash, N.; Wurst, W. Specification of midbrain territory. Cell Tissue Res. 2004, 318, 5-14. [CrossRef] [PubMed]

14. Ono, Y.; Nakatani, T.; Sakamoto, Y.; Mizuhara, E.; Minaki, Y.; Kumai, M.; Hamaguchi, A.; Nishimura, M.; Inoue, Y.; Hayashi, H.; et al. Differences in neurogenic potential in floor plate cells along an anteroposterior location: Midbrain dopaminergic neurons originate from mesencephalic floor plate cells. Development 2007, 134, 3213-3225. [CrossRef]

15. Bonilla, S.; Hall, A.C.; Pinto, L.; Attardo, A.; Gotz, M.; Huttner, W.B.; Arenas, E. Identification of midbrain floor plate radial glia-like cells as dopaminergic progenitors. Glia 2008, 56, 809-820. [CrossRef]

16. Veenvliet, J.V.; Smidt, M.P. Molecular mechanisms of dopaminergic subset specification: Fundamental aspects and clinical perspectives. Cell. Mol. Life Sci. 2014, 71, 4703-4727. [CrossRef] [PubMed]

17. Joksimovic, M.; Awatramani, R. Wnt/beta-catenin signaling in midbrain dopaminergic neuron specification and neurogenesis. J. Mol. Cell Biol. 2014, 6, 27-33. [CrossRef]

18. Wurst, W.; Prakash, N. Wnt1-regulated genetic networks in midbrain dopaminergic neuron development. J. Mol. Cell Biol. 2014, 6, 34-41. [CrossRef]

19. Jovanovic, V.M.; Salti, A.; Tilleman, H.; Zega, K.; Jukic, M.M.; Zou, H.; Friedel, R.H.; Prakash, N.; Blaess, S.; Edenhofer, F.; et al. BMP/SMAD Pathway Promotes Neurogenesis of Midbrain Dopaminergic Neurons In Vivo and in Human Induced Pluripotent and Neural Stem Cells. J. Neurosci. 2018, 38, 1662-1676. [CrossRef]

20. Puelles, E.; Acampora, D.; Lacroix, E.; Signore, M.; Annino, A.; Tuorto, F.; Filosa, S.; Corte, G.; Wurst, W.; Ang, S.L.; et al. Otx dose-dependent integrated control of antero-posterior and dorso-ventral patterning of midbrain. Nat. Neurosci. 2003, 6, 453-460. [CrossRef]

21. Brodski, C.; Weisenhorn, D.M.; Signore, M.; Sillaber, I.; Oesterheld, M.; Broccoli, V.; Acampora, D.; Simeone, A.; Wurst, W. Location and size of dopaminergic and serotonergic cell populations are controlled by the position of the midbrain-hindbrain organizer. J. Neurosci. 2003, 23, 4199-4207. [CrossRef]

22. Smidt, M.P.; Asbreuk, C.H.; Cox, J.J.; Chen, H.; Johnson, R.L.; Burbach, J.P. A second independent pathway for development of mesencephalic dopaminergic neurons requires Lmx1b. Nat. Neurosci. 2000, 3, 337-341. [CrossRef] [PubMed]

23. Andersson, E.; Tryggvason, U.; Deng, Q.; Friling, S.; Alekseenko, Z.; Robert, B.; Perlmann, T.; Ericson, J. Identification of intrinsic determinants of midbrain dopamine neurons. Cell 2006, 124, 393-405. [CrossRef] [PubMed] 
24. Lin, W.; Metzakopian, E.; Mavromatakis, Y.E.; Gao, N.; Balaskas, N.; Sasaki, H.; Briscoe, J.; Whitsett, J.A.; Goulding, M.; Kaestner, K.H.; et al. Foxa1 and Foxa2 function both upstream of and cooperatively with Lmx1a and Lmx1b in a feedforward loop promoting mesodiencephalic dopaminergic neuron development. Dev. Biol. 2009, 333, 386-396. [CrossRef] [PubMed]

25. Nakatani, T.; Kumai, M.; Mizuhara, E.; Minaki, Y.; Ono, Y. Lmx1a and Lmx1b cooperate with Foxa2 to coordinate the specification of dopaminergic neurons and control of floor plate cell differentiation in the developing mesencephalon. Dev. Biol. 2010, 339, 101-113. [CrossRef] [PubMed]

26. Yan, C.H.; Levesque, M.; Claxton, S.; Johnson, R.L.; Ang, S.L. Lmx1a and lmx1b function cooperatively to regulate proliferation, specification, and differentiation of midbrain dopaminergic progenitors. J. Neurosci. 2011, 31, 12413-12425. [CrossRef] [PubMed]

27. Deng, Q.; Andersson, E.; Hedlund, E.; Alekseenko, Z.; Coppola, E.; Panman, L.; Millonig, J.H.; Brunet, J.F.; Ericson, J.; Perlmann, T. Specific and integrated roles of Lmx1a, Lmx1b and Phox2a in ventral midbrain development. Development 2011, 138, 3399-3408. [CrossRef]

28. Sherf, O.; Nashelsky Zolotov, L.; Liser, K.; Tilleman, H.; Jovanovic, V.M.; Zega, K.; Jukic, M.M.; Brodski, C. Otx2 Requires Lmx1b to Control the Development of Mesodiencephalic Dopaminergic Neurons. PLoS ONE 2015, 10, e0139697. [CrossRef]

29. Andersson, E.; Jensen, J.B.; Parmar, M.; Guillemot, F.; Bjorklund, A. Development of the mesencephalic dopaminergic neuron system is compromised in the absence of neurogenin 2. Development 2006, 133, 507-516. [CrossRef]

30. Kele, J.; Simplicio, N.; Ferri, A.L.; Mira, H.; Guillemot, F.; Arenas, E.; Ang, S.L. Neurogenin 2 is required for the development of ventral midbrain dopaminergic neurons. Development 2006, 133, 495-505. [CrossRef]

31. Simon, H.H.; Saueressig, H.; Wurst, W.; Goulding, M.D.; O’Leary, D.D. Fate of midbrain dopaminergic neurons controlled by the engrailed genes. J. Neurosci. 2001, 21, 3126-3134. [CrossRef] [PubMed]

32. Alberi, L.; Sgado, P.; Simon, H.H. Engrailed genes are cell-autonomously required to prevent apoptosis in mesencephalic dopaminergic neurons. Development 2004, 131, 3229-3236. [CrossRef] [PubMed]

33. Sgado, P.; Alberi, L.; Gherbassi, D.; Galasso, S.L.; Ramakers, G.M.; Alavian, K.N.; Smidt, M.P.; Dyck, R.H.; Simon, H.H. Slow progressive degeneration of nigral dopaminergic neurons in postnatal Engrailed mutant mice. Proc. Natl. Acad. Sci. USA 2006, 103, 15242-15247. [CrossRef] [PubMed]

34. Sonnier, L.; Le Pen, G.; Hartmann, A.; Bizot, J.C.; Trovero, F.; Krebs, M.O.; Prochiantz, A. Progressive loss of dopaminergic neurons in the ventral midbrain of adult mice heterozygote for Engrailed1. J. Neurosci. 2007, 27, 1063-1071. [CrossRef] [PubMed]

35. Castillo, S.O.; Baffi, J.S.; Palkovits, M.; Goldstein, D.S.; Kopin, I.J.; Witta, J.; Magnuson, M.A.; Nikodem, V.M. Dopamine biosynthesis is selectively abolished in substantia nigra/ventral tegmental area but not in hypothalamic neurons in mice with targeted disruption of the Nurr1 gene. Mol. Cell. Neurosci. 1998, 11, 36-46. [CrossRef] [PubMed]

36. Saucedo-Cardenas, O.; Quintana-Hau, J.D.; Le, W.D.; Smidt, M.P.; Cox, J.J.; de Mayo, F.; Burbach, J.P.; Conneely, O.M. Nurr1 is essential for the induction of the dopaminergic phenotype and the survival of ventral mesencephalic late dopaminergic precursor neurons. Proc. Natl. Acad. Sci. USA 1998, 95, 4013-4018. [CrossRef] [PubMed]

37. Zetterstrom, R.H.; Solomin, L.; Jansson, L.; Hoffer, B.J.; Olson, L.; Perlmann, T. Dopamine neuron agenesis in Nurr1-deficient mice. Science 1997, 276, 248-250. [CrossRef] [PubMed]

38. Kadkhodaei, B.; Ito, T.; Joodmardi, E.; Mattsson, B.; Rouillard, C.; Carta, M.; Muramatsu, S.; Sumi-Ichinose, C.; Nomura, T.; Metzger, D.; et al. Nurr1 is required for maintenance of maturing and adult midbrain dopamine neurons. J. Neurosci. 2009, 29, 15923-15932. [CrossRef] [PubMed]

39. Nunes, I.; Tovmasian, L.T.; Silva, R.M.; Burke, R.E.; Goff, S.P. Pitx3 is required for development of substantia nigra dopaminergic neurons. Proc. Natl. Acad. Sci. USA 2003, 100, 4245-4250. [CrossRef] [PubMed]

40. Connolly, B.S.; Lang, A.E. Pharmacological treatment of Parkinson disease: A review. JAMA 2014, 311, 1670-1683. [CrossRef]

41. Barker, R.A.; Parmar, M.; Studer, L.; Takahashi, J. Human Trials of Stem Cell-Derived Dopamine Neurons for Parkinson's Disease: Dawn of a New Era. Cell Stem Cell 2017, 21, 569-573. [CrossRef] [PubMed]

42. Chambers, S.M.; Fasano, C.A.; Papapetrou, E.P.; Tomishima, M.; Sadelain, M.; Studer, L. Highly efficient neural conversion of human ES and iPS cells by dual inhibition of SMAD signaling. Nat. Biotechnol. 2009, 27, 275-280. [CrossRef] [PubMed] 
43. Kriks, S.; Shim, J.W.; Piao, J.; Ganat, Y.M.; Wakeman, D.R.; Xie, Z.; Carrillo-Reid, L.; Auyeung, G.; Antonacci, C.; Buch, A.; et al. Dopamine neurons derived from human ES cells efficiently engraft in animal models of Parkinson's disease. Nature 2011, 480, 547-551. [CrossRef]

44. Salti, A.; Nat, R.; Neto, S.; Puschban, Z.; Wenning, G.; Dechant, G. Expression of early developmental markers predicts the efficiency of embryonic stem cell differentiation into midbrain dopaminergic neurons. Stem Cells Dev. 2013, 22, 397-411. [CrossRef] [PubMed]

45. Deussing, J.M. Targeted mutagenesis tools for modelling psychiatric disorders. Cell Tissue Res. 2013, 354, 9-25. [CrossRef]

46. La Manno, G.; Gyllborg, D.; Codeluppi, S.; Nishimura, K.; Salto, C.; Zeisel, A.; Borm, L.E.; Stott, S.R.W.; Toledo, E.M.; Villaescusa, J.C.; et al. Molecular Diversity of Midbrain Development in Mouse, Human, and Stem Cells. Cell 2016, 167, 566. [CrossRef] [PubMed]

47. Breger, L.S.; Fuzzati Armentero, M.T. Genetically engineered animal models of Parkinson's disease: From worm to rodent. Eur. J. Neurosci. 2018. [CrossRef]

48. Ornitz, D.M.; Itoh, N. The Fibroblast Growth Factor signaling pathway. Wiley Interdiscip. Rev. Dev. Biol. 2015, 4, 215-266. [CrossRef]

49. Förthmann, B.; Aletta, J.M.; Lee, Y.-W.; Terranova, C.; Birkaya, B.; Stachowiak, E.K.; Stachowiak, M.K.; Claus, P. Coalition of Nuclear Receptors in the Nervous System. J. Cell. Physiol. 2015, 230, 2875-2880. [CrossRef]

50. Crossley, P.H.; Martinez, S.; Martin, G.R. Midbrain development induced by FGF8 in the chick embryo. Nature 1996, 380, 66-68. [CrossRef]

51. Olsen, S.K.; Li, J.Y.H.; Bromleigh, C.; Eliseenkova, A.V.; Ibrahimi, O.A.; Lao, Z.; Zhang, F.; Linhardt, R.J.; Joyner, A.L.; Mohammadi, M. Structural basis by which alternative splicing modulates the organizer activity of FGF8 in the brain. Genes Dev. 2006, 20, 185-198. [CrossRef] [PubMed]

52. Xu, J.; Liu, Z.; Ornitz, D.M. Temporal and spatial gradients of Fgf8 and Fgf17 regulate proliferation and differentiation of midline cerebellar structures. Development 2000, 127, 1833-1843.

53. Gimeno, L.; Brulet, P.; Martinez, S. Study of Fgf15 gene expression in developing mouse brain. Gene Expr. Patterns 2003, 3, 473-481. [CrossRef]

54. Fischer, T.; Faus-Kessler, T.; Welzl, G.; Simeone, A.; Wurst, W.; Prakash, N. Fgf15-mediated control of neurogenic and proneural gene expression regulates dorsal midbrain neurogenesis. Dev. Biol. 2011, 350, 496-510. [CrossRef]

55. Chen, Y.; Mohammadi, M.; Flanagan, J.G. Graded levels of FGF protein span the midbrain and can instruct graded induction and repression of neural mapping labels. Neuron 2009, 62, 773-780. [CrossRef] [PubMed]

56. Lahti, L.; Saarimaki-Vire, J.; Rita, H.; Partanen, J. FGF signaling gradient maintains symmetrical proliferative divisions of midbrain neuronal progenitors. Dev. Biol. 2011, 349, 270-282. [CrossRef] [PubMed]

57. Saarimaki-Vire, J.; Peltopuro, P.; Lahti, L.; Naserke, T.; Blak, A.A.; Vogt Weisenhorn, D.M.; Yu, K.; Ornitz, D.M.; Wurst, W.; Partanen, J. Fibroblast growth factor receptors cooperate to regulate neural progenitor properties in the developing midbrain and hindbrain. J. Neurosci. 2007, 27, 8581-8592. [CrossRef]

58. Lao, Z.; Raju, G.P.; Bai, C.B.; Joyner, A.L. MASTR: A technique for mosaic mutant analysis with spatial and temporal control of recombination using conditional floxed alleles in mice. Cell Rep. 2012, 2, 386-396. [CrossRef]

59. Jukkola, T.; Lahti, L.; Naserke, T.; Wurst, W.; Partanen, J. FGF regulated gene-expression and neuronal differentiation in the developing midbrain-hindbrain region. Dev. Biol. 2006, 297, 141-157. [CrossRef]

60. Bottcher, R.T.; Pollet, N.; Delius, H.; Niehrs, C. The transmembrane protein XFLRT3 forms a complex with FGF receptors and promotes FGF signalling. Nat. Cell Biol. 2004, 6, 38-44. [CrossRef]

61. Haines, B.P.; Wheldon, L.M.; Summerbell, D.; Heath, J.K.; Rigby, P.W.J. Regulated expression of FLRT genes implies a functional role in the regulation of FGF signalling during mouse development. Dev. Biol. 2006, 297, 14-25. [CrossRef] [PubMed]

62. Hirate, Y.; Okamoto, H. Canopy1, a novel regulator of FGF signaling around the midbrain-hindbrain boundary in zebrafish. Curr. Biol. 2006, 16, 421-427. [CrossRef] [PubMed]

63. Matsui, T.; Thitamadee, S.; Murata, T.; Kakinuma, H.; Nabetani, T.; Hirabayashi, Y.; Hirate, Y.; Okamoto, H.; Bessho, Y. Canopy1, a positive feedback regulator of FGF signaling, controls progenitor cell clustering during Kupffer's vesicle organogenesis. Proc. Natl. Acad. Sci. USA 2011, 108, 9881-9886. [CrossRef] [PubMed] 
64. Neben, C.L.; Lo, M.; Jura, N.; Klein, O.D. Feedback regulation of RTK signaling in development. Dev. Biol. 2017. [CrossRef] [PubMed]

65. Harada, H.; Sato, T.; Nakamura, H. Fgf8 signaling for development of the midbrain and hindbrain. Dev. Growth Differ. 2016, 58, 437-445. [CrossRef]

66. Ye, W.; Shimamura, K.; Rubenstein, J.L.; Hynes, M.A.; Rosenthal, A. FGF and Shh signals control dopaminergic and serotonergic cell fate in the anterior neural plate. Cell 1998, 93, 755-766. [CrossRef]

67. Chi, C.L.; Martinez, S.; Wurst, W.; Martin, G.R. The isthmic organizer signal FGF8 is required for cell survival in the prospective midbrain and cerebellum. Development 2003, 130, 2633-2644. [CrossRef] [PubMed]

68. Trokovic, R.; Jukkola, T.; Saarimaki, J.; Peltopuro, P.; Naserke, T.; Weisenhorn, D.M.; Trokovic, N.; Wurst, W.; Partanen, J. Fgfr1-dependent boundary cells between developing mid- and hindbrain. Dev. Biol. 2005, 278, 428-439. [CrossRef]

69. Sunmonu, N.A.; Li, K.; Guo, Q.; Li, J.Y. Gbx2 and Fgf8 are sequentially required for formation of the midbrain-hindbrain compartment boundary. Development 2011, 138, 725-734. [CrossRef]

70. Liu, A.; Losos, K.; Joyner, A.L. FGF8 can activate Gbx2 and transform regions of the rostral mouse brain into a hindbrain fate. Development 1999, 126, 4827-4838.

71. Martinez, S.; Crossley, P.H.; Cobos, I.; Rubenstein, J.L.; Martin, G.R. FGF8 induces formation of an ectopic isthmic organizer and isthmocerebellar development via a repressive effect on Otx2 expression. Development 1999, 126, 1189-1200. [PubMed]

72. Sato, T.; Araki, I.; Nakamura, H. Inductive signal and tissue responsiveness defining the tectum and the cerebellum. Development 2001, 128, 2461-2469. [PubMed]

73. Araki, I.; Nakamura, H. Engrailed defines the position of dorsal di-mesencephalic boundary by repressing diencephalic fate. Development 1999, 126, 5127-5135. [PubMed]

74. Liu, A.; Joyner, A.L. EN and GBX2 play essential roles downstream of FGF8 in patterning the mouse $\mathrm{mid} /$ hindbrain region. Development 2001, 128, 181-191. [PubMed]

75. Lahti, L.; Peltopuro, P.; Piepponen, T.P.; Partanen, J. Cell-autonomous FGF signaling regulates anteroposterior patterning and neuronal differentiation in the mesodiencephalic dopaminergic progenitor domain. Development 2012, 139, 894-905. [CrossRef] [PubMed]

76. Kee, N.; Volakakis, N.; Kirkeby, A.; Dahl, L.; Storvall, H.; Nolbrant, S.; Lahti, L.; Bjorklund, A.K.; Gillberg, L.; Joodmardi, E.; et al. Single-Cell Analysis Reveals a Close Relationship between Differentiating Dopamine and Subthalamic Nucleus Neuronal Lineages. Cell Stem Cell 2017, 20, 29-40. [CrossRef] [PubMed]

77. Nouri, N.; Awatramani, R. A novel floor plate boundary defined by adjacent En1 and Dbx1 microdomains distinguishes midbrain dopamine and hypothalamic neurons. Development 2017, 144, 916-927. [CrossRef]

78. Asbreuk, C.H.; Vogelaar, C.F.; Hellemons, A.; Smidt, M.P.; Burbach, J.P. CNS expression pattern of Lmx1b and coexpression with ptx genes suggest functional cooperativity in the development of forebrain motor control systems. Mol. Cell. Neurosci. 2002, 21, 410-420. [CrossRef]

79. Ellisor, D.; Rieser, C.; Voelcker, B.; Machan, J.T.; Zervas, M. Genetic dissection of midbrain dopamine neuron development in vivo. Dev. Biol. 2012, 372, 249-262. [CrossRef]

80. Poulin, J.-F.; Zou, J.; Drouin-Ouellet, J.; Kim, K.-Y.A.; Cicchetti, F.; Awatramani, R.B. Defining midbrain dopaminergic neuron diversity by single-cell gene expression profiling. Cell Rep. 2014, 9, 930-943. [CrossRef]

81. McGowan, L.D.; Alaama, R.A.; Striedter, G.F. FGF2 delays tectal neurogenesis, increases tectal cell numbers, and alters tectal lamination in embryonic chicks. PLOS ONE 2013, 8, e79949. [CrossRef] [PubMed]

82. Sato, T.; Shimazaki, T.; Naka, H.; Fukami, S.-I.; Satoh, Y.; Okano, H.; Lax, I.; Schlessinger, J.; Gotoh, N. FRS2 $\alpha$ regulates Erk levels to control a self-renewal target Hes1 and proliferation of FGF-responsive neural stem/progenitor cells. Stem Cells 2010, 28, 1661-1673. [CrossRef] [PubMed]

83. Kameda, Y.; Saitoh, T.; Fujimura, T. Hes1 regulates the number and anterior-posterior patterning of mesencephalic dopaminergic neurons at the mid/hindbrain boundary (isthmus). Dev. Biol. 2011, 358, 91-101. [CrossRef] [PubMed]

84. Liu, A.; Li, J.Y.; Bromleigh, C.; Lao, Z.; Niswander, L.A.; Joyner, A.L. FGF17b and FGF18 have different midbrain regulatory properties from FGF8b or activated FGF receptors. Development 2003, 130, 6175-6185. [CrossRef] [PubMed]

85. Yamauchi, K.; Mizushima, S.; Tamada, A.; Yamamoto, N.; Takashima, S.; Murakami, F. FGF8 signaling regulates growth of midbrain dopaminergic axons by inducing semaphorin 3F. J. Neurosci. 2009, 29, 4044-4055. [CrossRef] [PubMed] 
86. Ohmachi, S.; Watanabe, Y.; Mikami, T.; Kusu, N.; Ibi, T.; Akaike, A.; Itoh, N. FGF-20, a novel neurotrophic factor, preferentially expressed in the substantia nigra pars compacta of rat brain. Biochem. Biophys. Res. Commun. 2000, 277, 355-360. [CrossRef]

87. Ohmachi, S.; Mikami, T.; Konishi, M.; Miyake, A.; Itoh, N. Preferential neurotrophic activity of fibroblast growth factor-20 for dopaminergic neurons through fibroblast growth factor receptor-1c. J. Neurosci. Res. 2003, 72, 436-443. [CrossRef]

88. Murase, S.; McKay, R.D. A specific survival response in dopamine neurons at most risk in Parkinson's disease. J. Neurosci. 2006, 26, 9750-9760. [CrossRef]

89. Sleeman, I.J.; Boshoff, E.L.; Duty, S. Fibroblast growth factor-20 protects against dopamine neuron loss in vitro and provides functional protection in the 6-hydroxydopamine-lesioned rat model of Parkinson's disease. Neuropharmacology 2012, 63, 1268-1277. [CrossRef]

90. IPDGC; WTCCC2. A two-stage meta-analysis identifies several new loci for Parkinson's disease. PLoS Genet. 2011, 7, e1002142. [CrossRef]

91. Murphy, M.; Drago, J.; Bartlett, P.F. Fibroblast growth factor stimulates the proliferation and differentiation of neural precursor cells in vitro. J. Neurosci. Res. 1990, 25, 463-475. [CrossRef] [PubMed]

92. Tropepe, V.; Sibilia, M.; Ciruna, B.G.; Rossant, J.; Wagner, E.F.; van der Kooy, D. Distinct neural stem cells proliferate in response to EGF and FGF in the developing mouse telencephalon. Dev. Biol. 1999, 208, 166-188. [CrossRef] [PubMed]

93. Lee, S.H.; Lumelsky, N.; Studer, L.; Auerbach, J.M.; McKay, R.D. Efficient generation of midbrain and hindbrain neurons from mouse embryonic stem cells. Nat. Biotechnol. 2000, 18, 675-679. [CrossRef] [PubMed]

94. Sánchez-Pernaute, R.; Studer, L.; Bankiewicz, K.S.; Major, E.O.; McKay, R.D. In vitro generation and transplantation of precursor-derived human dopamine neurons. J. Neurosci. Res. 2001, 65, 284-288. [CrossRef] [PubMed]

95. Friling, S.; Andersson, E.; Thompson, L.H.; Jonsson, M.E.; Hebsgaard, J.B.; Nanou, E.; Alekseenko, Z.; Marklund, U.; Kjellander, S.; Volakakis, N.; et al. Efficient production of mesencephalic dopamine neurons by Lmx1a expression in embryonic stem cells. Proc. Natl. Acad. Sci. USA 2009, 106, 7613-7618. [CrossRef] [PubMed]

96. Kim, J.; Su, S.C.; Wang, H.; Cheng, A.W.; Cassady, J.P.; Lodato, M.A.; Lengner, C.J.; Chung, C.Y.; Dawlaty, M.M.; Tsai, L.H.; et al. Functional integration of dopaminergic neurons directly converted from mouse fibroblasts. Cell Stem Cell 2011, 9, 413-419. [CrossRef]

97. Kirkeby, A.; Nolbrant, S.; Tiklova, K.; Heuer, A.; Kee, N.; Cardoso, T.; Ottosson, D.R.; Lelos, M.J.; Rifes, P.; Dunnett, S.B.; et al. Predictive Markers Guide Differentiation to Improve Graft Outcome in Clinical Translation of hESC-Based Therapy for Parkinson's Disease. Cell Stem Cell 2017, 20, 135-148. [CrossRef]

98. Jaeger, I.; Arber, C.; Risner-Janiczek, J.R.; Kuechler, J.; Pritzsche, D.; Chen, I.C.; Naveenan, T.; Ungless, M.A.; Li, M. Temporally controlled modulation of FGF/ERK signaling directs midbrain dopaminergic neural progenitor fate in mouse and human pluripotent stem cells. Development 2011, 138, 4363-4374. [CrossRef]

99. Nolbrant, S.; Heuer, A.; Parmar, M.; Kirkeby, A. Generation of high-purity human ventral midbrain dopaminergic progenitors for in vitro maturation and intracerebral transplantation. Nat. Protoc. 2017, 12, 1962-1979. [CrossRef]

100. Briscoe, J.; Thérond, P.P. The mechanisms of Hedgehog signalling and its roles in development and disease. Nat. Rev. Mol. Cell Biol. 2013, 14, 416-429. [CrossRef]

101. Pereira, J.; Johnson, W.E.; O’Brien, S.J.; Jarvis, E.D.; Zhang, G.; Gilbert, M.T.P.; Vasconcelos, V.; Antunes, A. Evolutionary genomics and adaptive evolution of the Hedgehog gene family (Shh, Ihh and Dhh) in vertebrates. PLoS ONE 2014, 9, e74132. [CrossRef]

102. Belgacem, Y.H.; Hamilton, A.M.; Shim, S.; Spencer, K.A.; Borodinsky, L.N. The Many Hats of Sonic Hedgehog Signaling in Nervous System Development and Disease. J. Dev. Biol. 2016, 4, 35. [CrossRef] [PubMed]

103. Petrov, K.; Wierbowski, B.M.; Salic, A. Sending and Receiving Hedgehog Signals. Annu. Rev. Cell Dev. Biol. 2017, 33, 145-168. [CrossRef] [PubMed]

104. Wang, B.; Fallon, J.F.; Beachy, P.A. Hedgehog-regulated processing of Gli3 produces an anterior/posterior repressor gradient in the developing vertebrate limb. Cell 2000, 100, 423-434. [CrossRef] 
105. Pan, Y.; Bai, C.B.; Joyner, A.L.; Wang, B. Sonic hedgehog signaling regulates Gli2 transcriptional activity by suppressing its processing and degradation. Mol. Cell. Biol. 2006, 26, 3365-3377. [CrossRef] [PubMed]

106. Persson, M.; Stamataki, D.; te Welscher, P.; Andersson, E.; Böse, J.; Rüther, U.; Ericson, J.; Briscoe, J. Dorsal-ventral patterning of the spinal cord requires Gli3 transcriptional repressor activity. Genes Dev. 2002, 16, 2865-2878. [CrossRef]

107. Wijgerde, M.; McMahon, J.A.; Rule, M.; McMahon, A.P. A direct requirement for Hedgehog signaling for normal specification of all ventral progenitor domains in the presumptive mammalian spinal cord. Genes Dev. 2002, 16, 2849-2864. [CrossRef]

108. Bai, C.B.; Stephen, D.; Joyner, A.L. All mouse ventral spinal cord patterning by hedgehog is Gli dependent and involves an activator function of Gli3. Dev. Cell 2004, 6, 103-115. [CrossRef]

109. Bai, C.B.; Auerbach, W.; Lee, J.S.; Stephen, D.; Joyner, A.L. Gli2, but not Gli1, is required for initial Shh signaling and ectopic activation of the Shh pathway. Development 2002, 129, 4753-4761.

110. Matise, M.P.; Epstein, D.J.; Park, H.L.; Platt, K.A.; Joyner, A.L. Gli2 is required for induction of floor plate and adjacent cells, but not most ventral neurons in the mouse central nervous system. Development 1998, 125, 2759-2770.

111. Park, H.L.; Bai, C.; Platt, K.A.; Matise, M.P.; Beeghly, A.; Hui, C.C.; Nakashima, M.; Joyner, A.L. Mouse Gli1 mutants are viable but have defects in $\mathrm{SHH}$ signaling in combination with a Gli2 mutation. Development 2000, 127, 1593-1605. [PubMed]

112. Dessaud, E.; Yang, L.L.; Hill, K.; Cox, B.; Ulloa, F.; Ribeiro, A.; Mynett, A.; Novitch, B.G.; Briscoe, J. Interpretation of the sonic hedgehog morphogen gradient by a temporal adaptation mechanism. Nature 2007, 450, 717-720. [CrossRef]

113. Harfe, B.D.; Scherz, P.J.; Nissim, S.; Tian, H.; McMahon, A.P.; Tabin, C.J. Evidence for an expansion-based temporal Shh gradient in specifying vertebrate digit identities. Cell 2004, 118, 517-528. [CrossRef] [PubMed]

114. Ahn, S.; Joyner, A.L. Dynamic changes in the response of cells to positive hedgehog signaling during mouse limb patterning. Cell 2004, 118, 505-516. [CrossRef] [PubMed]

115. Bangs, F.; Anderson, K.V. Primary Cilia and Mammalian Hedgehog Signaling. Cold Spring Harb. Perspect. Biol. 2017, 9, a028175. [CrossRef] [PubMed]

116. Allen, B.L.; Song, J.Y.; Izzi, L.; Althaus, I.W.; Kang, J.-S.; Charron, F.; Krauss, R.S.; McMahon, A.P. Overlapping roles and collective requirement for the coreceptors GAS1, CDO, and BOC in SHH pathway function. Dev. Cell 2011, 20, 775-787. [CrossRef] [PubMed]

117. Izzi, L.; Lévesque, M.; Morin, S.; Laniel, D.; Wilkes, B.C.; Mille, F.; Krauss, R.S.; McMahon, A.P.; Allen, B.L.; Charron, F. Boc and Gas1 each form distinct Shh receptor complexes with Ptch1 and are required for Shh-mediated cell proliferation. Dev. Cell 2011, 20, 788-801. [CrossRef] [PubMed]

118. Ang, S.L.; Wierda, A.; Wong, D.; Stevens, K.A.; Cascio, S.; Rossant, J.; Zaret, K.S. The formation and maintenance of the definitive endoderm lineage in the mouse: Involvement of HNF3/forkhead proteins. Development 1993, 119, 1301-1315.

119. Metzakopian, E.; Lin, W.; Salmon-Divon, M.; Dvinge, H.; Andersson, E.; Ericson, J.; Perlmann, T.; Whitsett, J.A.; Bertone, P.; Ang, S.L. Genome-wide characterization of Foxa2 targets reveals upregulation of floor plate genes and repression of ventrolateral genes in midbrain dopaminergic progenitors. Development 2012, 139, 2625-2634. [CrossRef] [PubMed]

120. Blaess, S.; Corrales, J.D.; Joyner, A.L. Sonic hedgehog regulates Gli activator and repressor functions with spatial and temporal precision in the mid/hindbrain region. Development 2006, 133, 1799-1809. [CrossRef] [PubMed]

121. Fogel, J.L.; Chiang, C.; Huang, X.; Agarwala, S. Ventral specification and perturbed boundary formation in the mouse midbrain in the absence of Hedgehog signaling. Dev. Dyn. 2008, 237, 1359-1372. [CrossRef] [PubMed]

122. Hayes, L.; Ralls, S.; Wang, H.; Ahn, S. Duration of Shh signaling contributes to mDA neuron diversity. Dev. Biol. 2013, 374, 115-126. [CrossRef] [PubMed]

123. Blaess, S.; Bodea, G.O.; Kabanova, A.; Chanet, S.; Mugniery, E.; Derouiche, A.; Stephen, D.; Joyner, A.L. Temporal-spatial changes in Sonic Hedgehog expression and signaling reveal different potentials of ventral mesencephalic progenitors to populate distinct ventral midbrain nuclei. Neural Dev. 2011, 6, 29. [CrossRef] [PubMed] 
124. Tang, M.; Luo, S.X.; Tang, V.; Huang, E.J. Temporal and spatial requirements of Smoothened in ventral midbrain neuronal development. Neural Dev. 2013, 8, 8. [CrossRef] [PubMed]

125. Perez-Balaguer, A.; Puelles, E.; Wurst, W.; Martinez, S. Shh dependent and independent maintenance of basal midbrain. Mech. Dev. 2009, 126, 301-313. [CrossRef] [PubMed]

126. Mavromatakis, Y.E.; Lin, W.; Metzakopian, E.; Ferri, A.L.; Yan, C.H.; Sasaki, H.; Whisett, J.; Ang, S.L. Foxa1 and Foxa2 positively and negatively regulate Shh signalling to specify ventral midbrain progenitor identity. Mech. Dev. 2011, 128, 90-103. [CrossRef] [PubMed]

127. Mesman, S.; von Oerthel, L.; Smidt, M.P. Mesodiencephalic Dopaminergic Neuronal Differentiation Does Not Involve GLI2A-Mediated SHH-Signaling and Is under the Direct Influence of Canonical WNT Signaling. PLoS ONE 2014, 9, e97926. [CrossRef] [PubMed]

128. Kwon, Y.-R.; Jeong, M.-H.; Leem, Y.-E.; Lee, S.-J.; Kim, H.-J.; Bae, G.-U.; Kang, J.-S. The Shh coreceptor Cdo is required for differentiation of midbrain dopaminergic neurons. Stem Cell Res. 2014, 13, 262-274. [CrossRef]

129. Verwey, M.; Grant, A.; Meti, N.; Adye-White, L.; Torres-Berrío, A.; Rioux, V.; Lévesque, M.; Charron, F.; Flores, C. Mesocortical Dopamine Phenotypes in Mice Lacking the Sonic Hedgehog Receptor Cdon. eNeuro 2016, 3. [CrossRef]

130. Feuerstein, M.; Chleilat, E.; Khakipoor, S.; Michailidis, K.; Ophoven, C.; Roussa, E. Expression patterns of key Sonic Hedgehog signaling pathway components in the developing and adult mouse midbrain and in the MN9D cell line. Cell Tissue Res. 2017. [CrossRef]

131. Hammond, R.; Blaess, S.; Abeliovich, A. Sonic hedgehog is a chemoattractant for midbrain dopaminergic axons. PLoS ONE 2009, 4, e7007. [CrossRef] [PubMed]

132. Kittappa, R.; Chang, W.W.; Awatramani, R.B.; McKay, R.D. The foxa2 gene controls the birth and spontaneous degeneration of dopamine neurons in old age. PLoS Biol. 2007, 5, e325. [CrossRef] [PubMed]

133. Joksimovic, M.; Anderegg, A.; Roy, A.; Campochiaro, L.; Yun, B.; Kittappa, R.; McKay, R.; Awatramani, R. Spatiotemporally separable Shh domains in the midbrain define distinct dopaminergic progenitor pools. Proc. Natl. Acad. Sci. USA 2009, 106, 19185-19190. [CrossRef] [PubMed]

134. Placzek, M.; Briscoe, J. The floor plate: Multiple cells, multiple signals. Nat. Rev. Neurosci. 2005, 6, $230-240$. [CrossRef] [PubMed]

135. Joksimovic, M.; Yun, B.A.; Kittappa, R.; Anderegg, A.M.; Chang, W.W.; Taketo, M.M.; McKay, R.D.; Awatramani, R.B. Wnt antagonism of Shh facilitates midbrain floor plate neurogenesis. Nat. Neurosci. 2009, 12, 125-131. [CrossRef] [PubMed]

136. Hayes, L.; Zhang, Z.; Albert, P.; Zervas, M.; Ahn, S. Timing of Sonic hedgehog and Gli1 expression segregates midbrain dopamine neurons. J. Comp. Neurol. 2011, 519, 3001-3018. [CrossRef] [PubMed]

137. Bye, C.R.; Thompson, L.H.; Parish, C.L. Birth dating of midbrain dopamine neurons identifies A9 enriched tissue for transplantation into parkinsonian mice. Exp. Neurol. 2012, 236, 58-68. [CrossRef] [PubMed]

138. Panman, L.; Papathanou, M.; Laguna, A.; Oosterveen, T.; Volakakis, N.; Acampora, D.; Kurtsdotter, I.; Yoshitake, T.; Kehr, J.; Joodmardi, E.; et al. Sox6 and Otx2 control the specification of substantia nigra and ventral tegmental area dopamine neurons. Cell Rep. 2014, 8, 1018-1025. [CrossRef]

139. Hynes, M.; Porter, J.A.; Chiang, C.; Chang, D.; Tessier-Lavigne, M.; Beachy, P.A.; Rosenthal, A. Induction of midbrain dopaminergic neurons by Sonic hedgehog. Neuron 1995, 15, 35-44. [CrossRef]

140. Hynes, M.; Stone, D.M.; Dowd, M.; Pitts-Meek, S.; Goddard, A.; Gurney, A.; Rosenthal, A. Control of cell pattern in the neural tube by the zinc finger transcription factor and oncogene Gli-1. Neuron 1997, 19, 15-26. [CrossRef]

141. Fedtsova, N.; Turner, E.E. Signals from the ventral midline and isthmus regulate the development of Brn3.0-expressing neurons in the midbrain. Mech. Dev. 2001, 105, 129-144. [CrossRef]

142. Gazea, M.; Tasouri, E.; Tolve, M.; Bosch, V.; Kabanova, A.; Gojak, C.; Kurtulmus, B.; Novikov, O.; Spatz, J.; Pereira, G.; et al. Primary cilia are critical for Sonic hedgehog-mediated dopaminergic neurogenesis in the embryonic midbrain. Dev. Biol. 2016, 409, 55-71. [CrossRef] [PubMed]

143. Kabanova, A.; Pabst, M.; Lorkowski, M.; Braganza, O.; Boehlen, A.; Nikbakht, N.; Pothmann, L.; Vaswani, A.R.; Musgrove, R.; Di Monte, D.A.; et al. Function and developmental origin of a mesocortical inhibitory circuit. Nat. Neurosci. 2015, 18, 872-882. [CrossRef] [PubMed]

144. Hui, C.-C.; Slusarski, D.; Platt, K.A.; Holmgren, R.; Joyner, A.L. Expression of three mouse homologs of the Drosophila segment polarity gene cubitus interruptus, Gli, Gli-2, and Gli-3, in ectoderm- and 
mesoderm-derived tissues suggests multiple roles during postimplantation development. Dev. Biol. 1994, 162, 402-413. [CrossRef] [PubMed]

145. Szabó, N.-E.; Zhao, T.; Cankaya, M.; Theil, T.; Zhou, X.; Alvarez-Bolado, G. Role of neuroepithelial Sonic hedgehog in hypothalamic patterning. J. Neurosci. 2009, 29, 6989-7002. [CrossRef] [PubMed]

146. Gazea, M.; Tasouri, E.; Heigl, T.; Bosch, V.; Tucker, K.L.; Blaess, S. Definition of a critical spatiotemporal window within which primary cilia control midbrain dopaminergic neurogenesis. Neurogenesis 2016, 3, e1248206. [CrossRef] [PubMed]

147. Steinbeck, J.A.; Studer, L. Moving stem cells to the clinic: Potential and limitations for brain repair. Neuron 2015, 86, 187-206. [CrossRef] [PubMed]

148. Ribes, V.; Balaskas, N.; Sasai, N.; Cruz, C.; Dessaud, E.; Cayuso, J.; Tozer, S.; Yang, L.L.; Novitch, B.; Marti, E.; et al. Distinct Sonic Hedgehog signaling dynamics specify floor plate and ventral neuronal progenitors in the vertebrate neural tube. Genes Dev. 2010, 24, 1186-1200. [CrossRef] [PubMed]

149. Fasano, C.A.; Chambers, S.M.; Lee, G.; Tomishima, M.J.; Studer, L. Efficient derivation of functional floor plate tissue from human embryonic stem cells. Cell Stem Cell 2010, 6, 336-347. [CrossRef] [PubMed]

150. Kirkeby, A.; Grealish, S.; Wolf, D.A.; Nelander, J.; Wood, J.; Lundblad, M.; Lindvall, O.; Parmar, M. Generation of Regionally Specified Neural Progenitors and Functional Neurons from Human Embryonic Stem Cells under Defined Conditions. Cell Rep. 2012, 1, 703-714. [CrossRef]

151. Steinbeck, J.A.; Choi, S.J.; Mrejeru, A.; Ganat, Y.; Deisseroth, K.; Sulzer, D.; Mosharov, E.V.; Studer, L. Optogenetics enables functional analysis of human embryonic stem cell-derived grafts in a Parkinson's disease model. Nat. Biotechnol. 2015, 33, 204-209. [CrossRef] [PubMed]

152. Castelo-Branco, G.; Wagner, J.; Rodriguez, F.J.; Kele, J.; Sousa, K.; Rawal, N.; Pasolli, H.A.; Fuchs, E.; Kitajewski, J.; Arenas, E. Differential regulation of midbrain dopaminergic neuron development by Wnt-1, Wnt-3a, and Wnt-5a. Proc. Natl. Acad. Sci. USA 2003, 100, 12747-12752. [CrossRef] [PubMed]

153. Prakash, N.; Brodski, C.; Naserke, T.; Puelles, E.; Gogoi, R.; Hall, A.; Panhuysen, M.; Echevarria, D.; Sussel, L.; Weisenhorn, D.M.; et al. A Wnt1-regulated genetic network controls the identity and fate of midbrain-dopaminergic progenitors in vivo. Development 2006, 133, 89-98. [CrossRef] [PubMed]

154. Andersson, E.R.; Prakash, N.; Cajanek, L.; Minina, E.; Bryja, V.; Bryjova, L.; Yamaguchi, T.P.; Hall, A.C.; Wurst, W.; Arenas, E. Wnt5a regulates ventral midbrain morphogenesis and the development of A9-A10 dopaminergic cells in vivo. PLoS ONE 2008, 3, e3517. [CrossRef] [PubMed]

155. Li, W.; Chen, S.; Li, J.-Y. Human induced pluripotent stem cells in Parkinson's disease: A novel cell source of cell therapy and disease modeling. Prog. Neurobiol. 2015, 134, 161-177. [CrossRef] [PubMed]

156. Tabar, V.; Studer, L. Pluripotent stem cells in regenerative medicine: Challenges and recent progress. Nat. Rev. Genet. 2014, 15, 82-92. [CrossRef] [PubMed]

157. Grainger, S.; Willert, K. Mechanisms of Wnt signaling and control. Wiley Interdiscip. Rev. Syst. Biol. Med. 2018, e1422. [CrossRef]

158. Loh, K.M.; van Amerongen, R.; Nusse, R. Generating Cellular Diversity and Spatial Form: Wnt Signaling and the Evolution of Multicellular Animals. Dev. Cell 2016, 38, 643-655. [CrossRef]

159. Nusse, R.; Clevers, H. Wnt/ $\beta$-Catenin Signaling, Disease, and Emerging Therapeutic Modalities. Cell 2017, 169, 985-999. [CrossRef]

160. Van Amerongen, R. Alternative Wnt pathways and receptors. Cold Spring Harb. Perspect. Biol. 2012, 4, a007914. [CrossRef]

161. Xiao, Q.; Chen, Z.; Jin, X.; Mao, R.; Chen, Z. The many postures of noncanonical Wnt signaling in development and diseases. Biomed. Pharmacother. 2017, 93, 359-369. [CrossRef] [PubMed]

162. Arenas, E. Wnt signaling in midbrain dopaminergic neuron development and regenerative medicine for Parkinson's disease. J. Mol. Cell Biol. 2014, 6, 42-53. [CrossRef] [PubMed]

163. Yang, J.; Brown, A.; Ellisor, D.; Paul, E.; Hagan, N.; Zervas, M. Dynamic temporal requirement of Wnt1 in midbrain dopamine neuron development. Development 2013, 140, 1342-1352. [CrossRef] [PubMed]

164. Andersson, E.R.; Salto, C.; Villaescusa, J.C.; Cajanek, L.; Yang, S.; Bryjova, L.; Nagy, I.I.; Vainio, S.J.; Ramirez, C.; Bryja, V.; et al. Wnt5a cooperates with canonical Wnts to generate midbrain dopaminergic neurons in vivo and in stem cells. Proc. Natl. Acad. Sci. USA 2013, 110, 610. [CrossRef] [PubMed]

165. Prakash, N.; Wurst, W. Development of dopaminergic neurons in the mammalian brain. Cell. Mol. Life Sci. 2006, 63, 187-206. [CrossRef] [PubMed] 
166. Bryja, V.; Schulte, G.; Rawal, N.; Grahn, A.; Arenas, E. Wnt-5a induces Dishevelled phosphorylation and dopaminergic differentiation via a CK1-dependent mechanism. J. Cell Sci. 2007, 120, 586-595. [CrossRef] [PubMed]

167. Schulte, G.; Bryja, V.; Rawal, N.; Castelo-Branco, G.; Sousa, K.M.; Arenas, E. Purified Wnt-5a increases differentiation of midbrain dopaminergic cells and dishevelled phosphorylation. J. Neurochem. 2005, 92, 1550-1553. [CrossRef] [PubMed]

168. Haegel, H.; Larue, L.; Ohsugi, M.; Fedorov, L.; Herrenknecht, K.; Kemler, R. Lack of beta-catenin affects mouse development at gastrulation. Development 1995, 121, 3529-3537.

169. Chilov, D.; Sinjushina, N.; Saarimaki-Vire, J.; Taketo, M.M.; Partanen, J. $\beta$-Catenin regulates intercellular signalling networks and cell-type specific transcription in the developing mouse midbrain-rhombomere 1 region. PLoS ONE 2010, 5, e10881. [CrossRef]

170. Joksimovic, M.; Patel, M.; Taketo, M.M.; Johnson, R.; Awatramani, R. Ectopic Wnt/ $\beta$-catenin signaling induces neurogenesis in the spinal cord and hindbrain floor plate. PLoS ONE 2012, 7, e30266. [CrossRef]

171. Nouri, N.; Patel, M.J.; Joksimovic, M.; Poulin, J.-F.; Anderegg, A.; Taketo, M.M.; Ma, Y.-C.; Awatramani, R. Excessive Wnt/ $\beta$-catenin signaling promotes midbrain floor plate neurogenesis, but results in vacillating dopamine progenitors. Mol. Cell. Neurosci. 2015, 68, 131-142. [CrossRef] [PubMed]

172. Tang, M.; Miyamoto, Y.; Huang, E.J. Multiple roles of $\beta$-catenin in controlling the neurogenic niche for midbrain dopamine neurons. Development 2009, 136, 2027-2038. [CrossRef] [PubMed]

173. Tang, M.; Villaescusa, J.C.; Luo, S.X.; Guitarte, C.; Lei, S.; Miyamoto, Y.; Taketo, M.M.; Arenas, E.; Huang, E.J. Interactions of $\mathrm{Wnt} / \beta$-catenin signaling and sonic hedgehog regulate the neurogenesis of ventral midbrain dopamine neurons. J. Neurosci. 2010, 30, 9280-9291. [CrossRef] [PubMed]

174. Chilov, D.; Sinjushina, N.; Rita, H.; Taketo, M.M.; Makela, T.P.; Partanen, J. Phosphorylated $\beta$-catenin localizes to centrosomes of neuronal progenitors and is required for cell polarity and neurogenesis in developing midbrain. Dev. Biol. 2011, 357, 259-268. [CrossRef]

175. Castelo-Branco, G.; Andersson, E.R.; Minina, E.; Sousa, K.M.; Ribeiro, D.; Kokubu, C.; Imai, K.; Prakash, N.; Wurst, W.; Arenas, E. Delayed dopaminergic neuron differentiation in Lrp6 mutant mice. Dev. Dyn. 2010, 239, 211-221. [CrossRef] [PubMed]

176. Fernando, C.V.; Kele, J.; Bye, C.R.; Niclis, J.C.; Alsanie, W.; Blakely, B.D.; Stenman, J.; Turner, B.J.; Parish, C.L. Diverse roles for Wnt7a in ventral midbrain neurogenesis and dopaminergic axon morphogenesis. Stem Cells Dev. 2014, 23, 1991-2003. [CrossRef] [PubMed]

177. Sousa, K.M.; Villaescusa, J.C.; Cajanek, L.; Ondr, J.K.; Castelo-Branco, G.; Hofstra, W.; Bryja, V.; Palmberg, C.; Bergman, T.; Wainwright, B.; et al. Wnt2 regulates progenitor proliferation in the developing ventral midbrain. J. Biol. Chem. 2010, 285, 7246-7253. [CrossRef] [PubMed]

178. Fischer, T.; Guimera, J.; Wurst, W.; Prakash, N. Distinct but redundant expression of the Frizzled Wnt receptor genes at signaling centers of the developing mouse brain. Neuroscience 2007, 147, 693-711. [CrossRef] [PubMed]

179. Rawal, N.; Castelo-Branco, G.; Sousa, K.M.; Kele, J.; Kobayashi, K.; Okano, H.; Arenas, E. Dynamic temporal and cell type-specific expression of Wnt signaling components in the developing midbrain. Exp. Cell Res. 2006, 312, 1626-1636. [CrossRef] [PubMed]

180. Tissir, F.; Goffinet, A.M. Shaping the nervous system: Role of the core planar cell polarity genes. Nat. Rev. Neurosci. 2013, 14, 525-535. [CrossRef] [PubMed]

181. Stuebner, S.; Faus-Kessler, T.; Fischer, T.; Wurst, W.; Prakash, N. Fzd3 and Fzd6 deficiency results in a severe midbrain morphogenesis defect. Dev. Dyn. 2010, 239, 246-260. [CrossRef] [PubMed]

182. Kele, J.; Andersson, E.R.; Villaescusa, J.C.; Cajanek, L.; Parish, C.L.; Bonilla, S.; Toledo, E.M.; Bryja, V.; Rubin, J.S.; Shimono, A.; et al. SFRP1 and 2 Dose-Dependently Regulate Midbrain Dopamine Neuron Development In vivo and in Embryonic Stem Cells. Stem Cells 2012, 30, 865-875. [CrossRef] [PubMed]

183. Blakely, B.D.; Bye, C.R.; Fernando, C.V.; Prasad, A.A.; Pasterkamp, R.J.; Macheda, M.L.; Stacker, S.A.; Parish, C.L. Ryk, a Receptor Regulating Wnt5a-Mediated Neurogenesis and Axon Morphogenesis of Ventral Midbrain Dopaminergic Neurons. Stem Cells Dev. 2013, 22, 2132-2144. [CrossRef]

184. Fukusumi, Y.; Meier, F.; Götz, S.; Matheus, F.; Irmler, M.; Beckervordersandforth, R.; Faus-Kessler, T.; Minina, E.; Rauser, B.; Zhang, J.; et al. Dickkopf 3 Promotes the Differentiation of a Rostrolateral Midbrain Dopaminergic Neuronal Subset In Vivo and from Pluripotent Stem Cells In Vitro in the Mouse. J. Neurosci. 2015, 35, 13385-13401. [CrossRef] [PubMed] 
185. Cruciat, C.-M.; Niehrs, C. Secreted and transmembrane wnt inhibitors and activators. Cold Spring Harb. Perspect. Biol. 2013, 5, a015081. [CrossRef] [PubMed]

186. Vogt Weisenhorn, D.M.; Giesert, F.; Wurst, W. Diversity matters- heterogeneity of dopaminergic neurons in the ventral mesencephalon and its relation to Parkinson's Disease. J. Neurochem. 2016, 139 (Suppl. 1), 8-26. [CrossRef] [PubMed]

187. Omodei, D.; Acampora, D.; Mancuso, P.; Prakash, N.; Di Giovannantonio, L.G.; Wurst, W.; Simeone, A. Anterior-posterior graded response to Otx2 controls proliferation and differentiation of dopaminergic progenitors in the ventral mesencephalon. Development 2008, 135, 3459-3470. [CrossRef] [PubMed]

188. Anderegg, A.; Lin, H.P.; Chen, J.A.; Caronia-Brown, G.; Cherepanova, N.; Yun, B.; Joksimovic, M.; Rock, J.; Harfe, B.D.; Johnson, R.; et al. An Lmx1b-miR135a2 Regulatory Circuit Modulates Wnt1/Wnt Signaling and Determines the Size of the Midbrain Dopaminergic Progenitor Pool. PLoS Genet. 2013, 9, e1003973. [CrossRef] [PubMed]

189. Momcilovic, O.; Liu, Q.; Swistowski, A.; Russo-Tait, T.; Zhao, Y.; Rao, M.S.; Zeng, X. Genome wide profiling of dopaminergic neurons derived from human embryonic and induced pluripotent stem cells. Stem Cells Dev. 2014, 23, 406-420. [CrossRef] [PubMed]

190. Li, W.; Ding, S. Small molecules that modulate embryonic stem cell fate and somatic cell reprogramming. Trends Pharmacol. Sci. 2010, 31, 36-45. [CrossRef] [PubMed]

191. Cajanek, L.; Ribeiro, D.; Liste, I.; Parish, C.L.; Bryja, V.; Arenas, E. Wnt/ $\beta$-catenin signaling blockade promotes neuronal induction and dopaminergic differentiation in embryonic stem cells. Stem Cells 2009, 27, 2917-2927. [CrossRef] [PubMed]

192. Cajanek, L.; Ganji, R.S.; Henriques-Oliveira, C.; Theofilopoulos, S.; Konik, P.; Bryja, V.; Arenas, E. Tiam1 regulates the Wnt/Dvl/Rac1 signaling pathway and the differentiation of midbrain dopaminergic neurons. Mol. Cell. Biol. 2013, 33, 59-70. [CrossRef] [PubMed]

193. Castelo-Branco, G.; Rawal, N.; Arenas, E. GSK-3ß inhibition/beta-catenin stabilization in ventral midbrain precursors increases differentiation into dopamine neurons. J. Cell Sci. 2004, 117, 5731-5737. [CrossRef] [PubMed]

194. Rhim, J.H.; Luo, X.; Xu, X.; Gao, D.; Zhou, T.; Li, F.; Qin, L.; Wang, P.; Xia, X.; Wong, S.T.C. A High-content screen identifies compounds promoting the neuronal differentiation and the midbrain dopamine neuron specification of human neural progenitor cells. Sci. Rep. 2015, 5, 16237. [CrossRef] [PubMed]

195. Xi, J.; Liu, Y.; Liu, H.; Chen, H.; Emborg, M.E.; Zhang, S.C. Specification of midbrain dopamine neurons from primate pluripotent stem cells. Stem Cells 2012, 30, 1655-1663. [CrossRef] [PubMed]

196. Okawa, S.; Salto, C.; Ravichandran, S.; Yang, S.; Toledo, E.M.; Arenas, E.; Del Sol, A. Transcriptional synergy as an emergent property defining cell subpopulation identity enables population shift. Nat. Commun. 2018, 9, 2595. [CrossRef]

197. Zeng, X.-S.; Geng, W.-S.; Jia, J.-J.; Chen, L.; Zhang, P.-P. Cellular and Molecular Basis of Neurodegeneration in Parkinson Disease. Front. Aging Neurosci. 2018, 10, 109. [CrossRef]

198. Awad, O.; Panicker, L.M.; Deranieh, R.M.; Srikanth, M.P.; Brown, R.A.; Voit, A.; Peesay, T.; Park, T.S.; Zambidis, E.T.; Feldman, R.A. Altered Differentiation Potential of Gaucher's Disease iPSC Neuronal Progenitors due to Wnt/beta-Catenin Downregulation. Stem Cell Rep. 2017, 9, 1853-1867. [CrossRef]

199. De Gregorio, R.; Pulcrano, S.; de Sanctis, C.; Volpicelli, F.; Guatteo, E.; von Oerthel, L.; Latagliata, E.C.; Esposito, R.; Piscitelli, R.M.; Perrone-Capano, C.; et al. miR-34b/c Regulates Wnt1 and Enhances Mesencephalic Dopaminergic Neuron Differentiation. Stem Cell Rep. 2018, 10, 1237-1250. [CrossRef]

200. Kim, H.S.; Kim, J.; Jo, Y.; Jeon, D.; Cho, Y.S. Direct lineage reprogramming of mouse fibroblasts to functional midbrain dopaminergic neuronal progenitors. Stem Cell Res. 2013, 12, 60-68. [CrossRef]

201. Di Rivetti Val Cervo, P.; Romanov, R.A.; Spigolon, G.; Masini, D.; Martin-Montanez, E.; Toledo, E.M.; La Manno, G.; Feyder, M.; Pifl, C.; Ng, Y.-H.; et al. Induction of functional dopamine neurons from human astrocytes in vitro and mouse astrocytes in a Parkinson's disease model. Nat. Biotechnol. 2017, 35, 444-452. [CrossRef] [PubMed]

202. Liss, B.; Franz, O.; Sewing, S.; Bruns, R.; Neuhoff, H.; Roeper, J. Tuning pacemaker frequency of individual dopaminergic neurons by Kv4.3L and KChip3.1 transcription. EMBO J. 2001, 20, 5715-5724. [CrossRef]

203. Serodio, P.; Rudy, B. Differential expression of $\mathrm{Kv} 4 \mathrm{~K}^{+}$channel subunits mediating subthreshold transient $\mathrm{K}^{+}$ (A-type) currents in rat brain. J. Neurophysiol. 1998, 79, 1081-1091. [CrossRef] [PubMed] 
204. Liang, C.L.; Sinton, C.M.; German, D.C. Midbrain dopaminergic neurons in the mouse: Co-localization with Calbindin-D28K and calretinin. Neuroscience 1996, 75, 523-533. [CrossRef]

205. Katagiri, T.; Watabe, T. Bone Morphogenetic Proteins. Cold Spring Harb. Perspect. Biol. 2016, 8. [CrossRef]

206. Chen, H.-L.; Panchision, D.M. Concise review: Bone morphogenetic protein pleiotropism in neural stem cells and their derivatives-Alternative pathways, convergent signals. Stem Cells 2007, 25, 63-68. [CrossRef]

207. Bond, A.M.; Bhalala, O.G.; Kessler, J.A. The dynamic role of bone morphogenetic proteins in neural stem cell fate and maturation. Dev. Neurobiol. 2012, 72, 1068-1084. [CrossRef]

208. Hegarty, S.V.; O'Keeffe, G.W.; Sullivan, A.M. BMP-Smad 1/5/8 signalling in the development of the nervous system. Prog. Neurobiol. 2013, 109, 28-41. [CrossRef]

209. Furuta, Y.; Piston, D.W.; Hogan, B.L. Bone morphogenetic proteins (BMPs) as regulators of dorsal forebrain development. Development 1997, 124, 2203-2212.

210. Liu, A.; Niswander, L.A. Bone morphogenetic protein signalling and vertebrate nervous system development. Nat. Rev. Neurosci. 2005, 6, 945-954. [CrossRef]

211. Arnold, S.J.; Maretto, S.; Islam, A.; Bikoff, E.K.; Robertson, E.J. Dose-dependent Smad1, Smad5 and Smad8 signaling in the early mouse embryo. Dev. Biol. 2006, 296, 104-118. [CrossRef] [PubMed]

212. Rosenzweig, B.L.; Imamura, T.; Okadome, T.; Cox, G.N.; Yamashita, H.; ten Dijke, P.; Heldin, C.H.; Miyazono, K. Cloning and characterization of a human type II receptor for bone morphogenetic proteins. Proc. Natl. Acad. Sci. USA 1995, 92, 7632-7636. [CrossRef] [PubMed]

213. Feng, X.-H.; Derynck, R. Specificity and versatility in tgf-beta signaling through Smads. Annu. Rev. Cell Dev. Biol. 2005, 21, 659-693. [CrossRef] [PubMed]

214. Derynck, R.; Zhang, Y.E. Smad-dependent and Smad-independent pathways in TGF-beta family signalling. Nature 2003, 425, 577-584. [CrossRef] [PubMed]

215. Jordan, J.; Böttner, M.; Schluesener, H.J.; Unsicker, K.; Krieglstein, K. Bone morphogenetic proteins: neurotrophic roles for midbrain dopaminergic neurons and implications of astroglial cells. Eur. J. Neurosci. 1997, 9, 1699-1709. [CrossRef] [PubMed]

216. Hegarty, S.V.; Sullivan, A.M.; O'Keeffe, G.W. BMP2 and GDF5 induce neuronal differentiation through a Smad dependant pathway in a model of human midbrain dopaminergic neurons. Mol. Cell. Neurosci. 2013, 56, 263-271. [CrossRef] [PubMed]

217. Panchision, D.M.; Pickel, J.M.; Studer, L.; Lee, S.H.; Turner, P.A.; Hazel, T.G.; McKay, R.D. Sequential actions of BMP receptors control neural precursor cell production and fate. Genes Dev. 2001, 15, 2094-2110. [CrossRef]

218. Tronche, F.; Kellendonk, C.; Kretz, O.; Gass, P.; Anlag, K.; Orban, P.C.; Bock, R.; Klein, R.; Schutz, G. Disruption of the glucocorticoid receptor gene in the nervous system results in reduced anxiety. Nat. Genet. 1999, 23, 99-103. [CrossRef]

219. Schulz, T.C.; Noggle, S.A.; Palmarini, G.M.; Weiler, D.A.; Lyons, I.G.; Pensa, K.A.; Meedeniya, A.C.B.; Davidson, B.P.; Lambert, N.A.; Condie, B.G. Differentiation of human embryonic stem cells to dopaminergic neurons in serum-free suspension culture. Stem Cells 2004, 22, 1218-1238. [CrossRef]

220. Liu, Q.; Pedersen, O.Z.; Peng, J.; Couture, L.A.; Rao, M.S.; Zeng, X. Optimizing dopaminergic differentiation of pluripotent stem cells for the manufacture of dopaminergic neurons for transplantation. Cytotherapy 2013, 15, 999-1010. [CrossRef]

221. Yang, H.; Wang, J.; Wang, F.; Liu, X.; Chen, H.; Duan, W.; Qu, T. Dopaminergic Neuronal Differentiation from the Forebrain-Derived Human Neural Stem Cells Induced in Cultures by Using a Combination of BMP-7 and Pramipexole with Growth Factors. Front. Neural Circuits 2016, 10, 29. [CrossRef]

222. Thier, M.; Wörsdörfer, P.; Lakes, Y.B.; Gorris, R.; Herms, S.; Opitz, T.; Seiferling, D.; Quandel, T.; Hoffmann, P.; Nöthen, M.M.; et al. Direct conversion of fibroblasts into stably expandable neural stem cells. Cell Stem Cell 2012, 10, 473-479. [CrossRef] [PubMed]

223. Kadari, A.; Lu, M.; Li, M.; Sekaran, T.; Thummer, R.P.; Guyette, N.; Chu, V.; Edenhofer, F. Excision of viral reprogramming cassettes by Cre protein transduction enables rapid, robust and efficient derivation of transgene-free human induced pluripotent stem cells. Stem Cell Res. Ther. 2014, 5, 47. [CrossRef] [PubMed]

224. Meyer, S.; Wörsdörfer, P.; Günther, K.; Thier, M.; Edenhofer, F. Derivation of Adult Human Fibroblasts and their Direct Conversion into Expandable Neural Progenitor Cells. J. Vis. Exp. 2015, e52831. [CrossRef] [PubMed] 
225. Kwok, C.K.; Ueda, Y.; Kadari, A.; Günther, K.; Ergün, S.; Heron, A.; Schnitzler, A.C.; Rook, M.; Edenhofer, F. Scalable stirred suspension culture for the generation of billions of human induced pluripotent stem cells using single-use bioreactors. J. Tissue Eng. Regener. Med. 2018, 12, e1076-e1087. [CrossRef] [PubMed]

226. Reinhardt, P.; Glatza, M.; Hemmer, K.; Tsytsyura, Y.; Thiel, C.S.; Hoing, S.; Moritz, S.; Parga, J.A.; Wagner, L.; Bruder, J.M.; et al. Derivation and expansion using only small molecules of human neural progenitors for neurodegenerative disease modeling. PLoS ONE 2013, 8, e59252. [CrossRef]

227. Joyner, A.L.; Liu, A.; Millet, S. Otx2, Gbx2 and Fgf8 interact to position and maintain a mid-hindbrain organizer. Curr. Opin. Cell Biol. 2000, 12, 736-741. [CrossRef]

228. Wurst, W.; Bally-Cuif, L. Neural plate patterning: Upstream and downstream of the isthmic organizer. Nat. Rev. Neurosci. 2001, 2, 99-108. [CrossRef]

229. Olander, S.; Nordstrom, U.; Patthey, C.; Edlund, T. Convergent Wnt and FGF signaling at the gastrula stage induce the formation of the isthmic organizer. Mech. Dev. 2006, 123, 166-176. [CrossRef]

230. Canning, C.A.; Lee, L.; Irving, C.; Mason, I.; Jones, C.M. Sustained interactive Wnt and FGF signaling is required to maintain isthmic identity. Dev. Biol. 2007, 305, 276-286. [CrossRef]

231. Dyer, C.; Blanc, E.; Hanisch, A.; Roehl, H.; Otto, G.W.; Yu, T.; Basson, M.A.; Knight, R. A bi-modal function of Wnt signalling directs an FGF activity gradient to spatially regulate neuronal differentiation in the midbrain. Development 2014, 141, 63-72. [CrossRef] [PubMed]

232. Wittmann, D.M.; Blochl, F.; Trumbach, D.; Wurst, W.; Prakash, N.; Theis, F.J. Spatial analysis of expression patterns predicts genetic interactions at the mid-hindbrain boundary. PLoS Comput. Biol. 2009, 5, e1000569. [CrossRef]

233. Danielian, P.S.; McMahon, A.P. Engrailed-1 as a target of the Wnt-1 signalling pathway in vertebrate midbrain development. Nature 1996, 383, 332-334. [CrossRef] [PubMed]

234. Gemel, J.; Jacobsen, C.; MacArthur, C.A. Fibroblast growth factor-8 expression is regulated by intronic engrailed and Pbx1-binding sites. J. Biol. Chem. 1999, 274, 6020-6026. [CrossRef] [PubMed]

235. Ardayfio, P.A.; Leung, A.; Park, J.; Hwang, D.Y.; Moran-Gates, T.; Choi, Y.K.; Carlezon, W.A., Jr.; Tarazi, F.I.; Kim, K.S. Pitx3-deficient aphakia mice display unique behavioral responses to psychostimulant and antipsychotic drugs. Neuroscience 2010, 166, 391-396. [CrossRef] [PubMed]

236. Kim, J.Y.; Lee, J.S.; Hwang, H.S.; Lee, D.R.; Park, C.-Y.; Jung, S.J.; You, Y.R.; Kim, D.-S.; Kim, D.-W. Wnt signal activation induces midbrain specification through direct binding of the $\beta$-catenin/TCF4 complex to the EN1 promoter in human pluripotent stem cells. Exp. Mol. Med. 2018, 50, 24. [CrossRef] [PubMed]

237. Nguyen, T.M.; Kabotyanski, E.B.; Dou, Y.; Reineke, L.C.; Zhang, P.; Zhang, X.H.-F.; Malovannaya, A.; Jung, S.Y.; Mo, Q.; Roarty, K.P.; et al. FGFR1-Activated Translation of WNT Pathway Components with Structured 5' UTRs Is Vulnerable to Inhibition of EIF4A-Dependent Translation Initiation. Cancer Res. 2018, 78, 4229-4240. [CrossRef]

238. Aman, A.; Piotrowski, T. Wnt/ $\beta$-catenin and Fgf signaling control collective cell migration by restricting chemokine receptor expression. Dev. Cell 2008, 15, 749-761. [CrossRef]

239. Dailey, L.; Ambrosetti, D.; Mansukhani, A.; Basilico, C. Mechanisms underlying differential responses to FGF signaling. Cytokine Growth Factor Rev. 2005, 16, 233-247. [CrossRef]

240. Ulloa, F.; Itasaki, N.; Briscoe, J. Inhibitory Gli3 activity negatively regulates Wnt/beta-catenin signaling. Curr. Biol. 2007, 17, 545-550. [CrossRef]

241. Lei, Q.; Jeong, Y.; Misra, K.; Li, S.; Zelman, A.K.; Epstein, D.J.; Matise, M.P. Wnt signaling inhibitors regulate the transcriptional response to morphogenetic Shh-Gli signaling in the neural tube. Dev. Cell 2006, 11, 325-337. [CrossRef]

242. Tasouri, E.; Tucker, K.L. Primary cilia and organogenesis: Is Hedgehog the only sculptor? Cell Tissue Res. 2011, 345, 21-40. [CrossRef] [PubMed]

243. Cai, J.; Schleidt, S.; Pelta-Heller, J.; Hutchings, D.; Cannarsa, G.; Iacovitti, L. BMP and TGF-beta pathway mediators are critical upstream regulators of Wnt signaling during midbrain dopamine differentiation in human pluripotent stem cells. Dev. Biol. 2013, 376, 62-73. [CrossRef] [PubMed]

244. Falk, S.; Wurdak, H.; Ittner, L.M.; Ille, F.; Sumara, G.; Schmid, M.-T.; Draganova, K.; Lang, K.S.; Paratore, C.; Leveen, P.; et al. Brain area-specific effect of TGF- $\beta$ signaling on Wnt-dependent neural stem cell expansion. Cell Stem Cell 2008, 2, 472-483. [CrossRef] [PubMed]

245. Veeck, J.; Dahl, E. Targeting the Wnt pathway in cancer: The emerging role of Dickkopf-3. Biochim. Biophys. Acta 2012, 1825, 18-28. [CrossRef] 
246. Zhang, J.; Götz, S.; Vogt Weisenhorn, D.M.; Simeone, A.; Wurst, W.; Prakash, N. A WNT1-regulated developmental gene cascade prevents dopaminergic neurodegeneration in adult En1(+/-) mice. Neurobiol. Dis. 2015, 82, 32-45. [CrossRef]

247. Rekaik, H.; Blaudin de The, F.-X.; Prochiantz, A.; Fuchs, J.; Joshi, R.L. Dissecting the role of Engrailed in adult dopaminergic neurons-Insights into Parkinson disease pathogenesis. FEBS Lett. 2015, 589, 3786-3794. [CrossRef]

248. Chung, S.; Leung, A.; Han, B.S.; Chang, M.Y.; Moon, J.I.; Kim, C.H.; Hong, S.; Pruszak, J.; Isacson, O.; Kim, K.S. Wnt1-lmx1a forms a novel autoregulatory loop and controls midbrain dopaminergic differentiation synergistically with the SHH-FoxA2 pathway. Cell Stem Cell 2009, 5, 646-658. [CrossRef] [PubMed]

249. Matthes, M.; Preusse, M.; Zhang, J.; Schechter, J.; Mayer, D.; Lentes, B.; Theis, F.; Prakash, N.; Wurst, W.; Trumbach, D. Mouse IDGenes: A reference database for genetic interactions in the developing mouse brain. Database 2014, 2014, bau083. [CrossRef]

250. Peng, C.; Aron, L.; Klein, R.; Li, M.; Wurst, W.; Prakash, N.; Le, W. Pitx3 is a critical mediator of GDNF-induced BDNF expression in nigrostriatal dopaminergic neurons. J. Neurosci. 2011, 31, 12802-12815. [CrossRef] [PubMed]

251. Prakash, N.; Wurst, W. A Wnt signal regulates stem cell fate and differentiation in vivo. Neurodegener. Dis. 2007, 4, 333-338. [CrossRef] [PubMed]

252. Hegarty, S.V.; Sullivan, A.M.; O'Keeffe, G.W. Roles for the TGF $\beta$ superfamily in the development and survival of midbrain dopaminergic neurons. Mol. Neurobiol. 2014, 50, 559-573. [CrossRef]

253. Pinho, S.; Niehrs, C. Dkk3 is required for TGF-beta signaling during Xenopus mesoderm induction. Differentiation 2007, 75, 957-967. [CrossRef] [PubMed]

254. Hsu, R.J.; Lin, C.C.; Su, Y.F.; Tsai, H.J. dickkopf-3-related gene regulates the expression of zebrafish myf5 gene through phosphorylated p38a-dependent Smad4 activity. J. Biol. Chem. 2011, 286, 6855-6864. [CrossRef] [PubMed]

255. Romero, D.; Kawano, Y.; Bengoa, N.; Walker, M.M.; Maltry, N.; Niehrs, C.; Waxman, J.; Kypta, R. Downregulation of Dickkopf-3 disrupts prostate acinar morphogenesis through TGF- $\beta$ /Smad signalling. J. Cell Sci. 2013, 126, 1858-1867. [CrossRef] [PubMed]

256. Li, Y.; Liu, H.; Liang, Y.; Peng, P.; Ma, X.; Zhang, X. DKK3 regulates cell proliferation, apoptosis and collagen synthesis in keloid fibroblasts via TGF- $\beta 1 /$ Smad signaling pathway. Biomed. Pharmacother. 2017, 91, 174-180. [CrossRef] [PubMed]

257. Itasaki, N.; Hoppler, S. Crosstalk between Wnt and bone morphogenic protein signaling: A turbulent relationship. Dev. Dyn. 2010, 239, 16-33. [CrossRef] [PubMed]

258. Arkell, R.; Beddington, R.S. BMP-7 influences pattern and growth of the developing hindbrain of mouse embryos. Development 1997, 124, 1-12. [PubMed] 